



\section{Driftreductie Lochmann dwarsstroomspuit met Air Closing System}

J.M.G.P. Michielsen, H. Stallinga, M. Snoussi, D.C. de Hoog, P. van Dalfsen, M. Wenneker \& J.C. van de Zande

Dit onderzoek is in samenwerking met Van der Linden Fruitteelt Machines te Dreumel uitgevoerd door de Stichting Wageningen Research (WR), business unit Agrosysteemkunde (projectnummer 3710460700).

WR is een onderdeel van Wageningen University \& Research, samenwerkingsverband tussen Wageningen University en de Stichting Wageningen Research.

Wageningen, december 2019

Rapport WPR-881 
Michielsen, J.M.G.P., H. Stallinga, M. Snoussi, D.C. de Hoog, P. van Dalfsen, M. Wenneker \& J.C. van de Zande, 2019. Driftreductie Lochmann dwarsstroomspuit met Air Closing System. Wageningen Research, Rapport WPR-881. 36 blz.; 11 fig.; 10 tab.; 21 ref.

Dit rapport is gratis te downloaden op https://doi.org/10.18174/471328

Results of spray drift experiments are presented of the Lochmann cross-flow fan orchard sprayer equipped with an Air Closing System (ACS) in comparison with a reference spray technique for fruit crop spraying in The Netherlands. The Lochmann cross-flow fan orchard sprayer with ACS was equipped with $90 \%$ drift reducing nozzles (Albuz TVI $8001 ; 7$ bar spray pressure). During the spray drift experiments the downwind outside $24 \mathrm{~m}$ of an apple orchard was sprayed at the full leaf stage (BBCH 90/92) using the fluorescent tracer Acid Yellow 250. Spray drift deposition was collected downwind on a mowed grass area up to $25 \mathrm{~m}$ distance from the last tree row. Airborne spray drift was measured at $7.5 \mathrm{~m}$ distance from the last tree row on a pole at which two lines with collectors were attached at $1 \mathrm{~m}$ spacing up to $10 \mathrm{~m}$ height. For the Lochmann cross-flow fan orchard sprayer equipped with Air Closing System and 90\% drift reducing nozzles spray drift reduction at 4.5-5.5 m distance from the last tree row was $98.4 \%$ in comparison with the reference spray application. Airborne spray drift was reduced by $97.0 \%$ for the Lochmann cross-flow fan orchard sprayer equipped with Air Closing System and $90 \%$ drift reducing nozzles.

Key words: orchard sprayer, spray drift, nozzle type, air assistance, spray drift reduction

(C) 2019 Wageningen, Stichting Wageningen Research, Wageningen Plant Research, Business unit Agrosysteemkunde, Postbus 16, 6700 AA Wageningen; T 03174807 00; www.wur.nl/plant-research

KvK: 09098104 te Arnhem

VAT NL no. 8113.83.696.B07

Stichting Wageningen Research. Alle rechten voorbehouden. Niets uit deze uitgave mag worden verveelvoudigd, opgeslagen in een geautomatiseerd gegevensbestand, of openbaar gemaakt, in enige vorm of op enige wijze, hetzij elektronisch, mechanisch, door fotokopieën, opnamen of enige andere manier zonder voorafgaande schriftelijke toestemming van Stichting Wageningen Research.

Stichting Wageningen Research is niet aansprakelijk voor eventuele schadelijke gevolgen die kunnen ontstaan bij gebruik van gegevens uit deze uitgave.

Rapport WPR-881

Foto omslag: Jan van de Zande (LochmannCF-ACS-jvdz_IMG_2512.JPG) 


\section{Inhoud}

Woord vooraf $\quad 5$

$\begin{array}{ll}\text { Samenvatting } & 7\end{array}$

$\begin{array}{ll}\text { Summary } & 9\end{array}$

$1 \quad$ Inleiding $r$

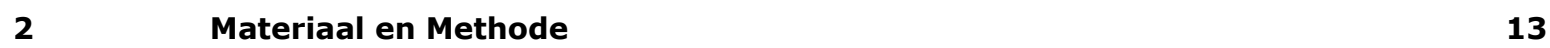

$\begin{array}{lll}2.1 & \text { Afstelling en beschrijving spuittechniek } & 13\end{array}$

2.1.1 Karakteristieken Munckhof dwarsstroomspuit $\quad 13$

2.1.2 Lochmann dwarsstroomspuit $\quad 13$

2.1.3 Samenvatting gebruikte spuittechnieken 16

$\begin{array}{lll}2.2 & \text { Beschrijving metingen en verwerking resultaten } & 17\end{array}$

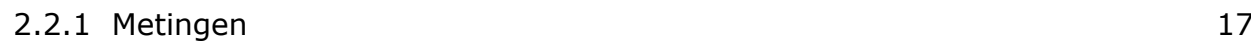

2.2.2 Analyses 18

$\begin{array}{ll}2.2 .3 \text { Berekeningen en statistiek } & 19\end{array}$

$\begin{array}{lll}2.3 & \text { Weersomstandigheden } & 20\end{array}$

$3 \quad$ Resultaten $r 22$

3.1 Drift naar de grond naast het perceel $\quad 22$

$\begin{array}{lll}3.2 & \text { Drift naar de lucht } & 24\end{array}$

4 Discussie $\quad 26$

$\begin{array}{llr}5 & \text { Conclusie } & \mathbf{2 7}\end{array}$

$\begin{array}{ll}\text { Literatuur } & 28\end{array}$

$\begin{array}{lll}\text { Bijlage } 1 & \text { Script statistische analyse } & 30\end{array}$

Bijlage 2 Weersomstandigheden tijdens de driftmetingen 31

Bijlage 3 Driftdepositie (\% van afgifte) op de grond naast het gewas 32

Bijlage 4 Driftdepositie (\% van afgifte) naar de lucht 34 



\section{Woord vooraf}

Emissie van gewasbeschermingsmiddelen verminderen is van groot belang voor de fruitteelt en speelt een belangrijke rol bij de invulling van beleid en regelgeving in Nederland. Toedieningstechnieken die de drift, het verwaaien van de spuitvloeistof tot buiten het doelgewas, reduceren zijn nodig om de beleidsdoelen te kunnen realiseren en om gewasbeschermingsmiddelen veilig te kunnen gebruiken. In deze rapportage wordt het onderzoek van een driftreducerende techniek in de fruitteelt beschreven. Driftonderzoek is gedaan aan de Lochmann dwarsstroomspuit uitgerust met Air Closing System en $90 \%$ driftreducerende spuitdoppen, in het volbladstadium van een appelboomgaard. De driftmetingen zijn uitgevoerd in het emissie proefveld voor de fruitteelt, een boomgaard van WUR op de Proeftuin Randwijk, met medewerking van de Proeftuin en WUR Unifarm.

Dit onderzoek is uitgevoerd in samenwerking met Van der Linden Fruitteelt Machines (Dreumel) en begeleid door dhr. R. van der Linden.

Wageningen, februari 2019 


\section{Samenvatting}

Uit eerdere driftmetingen is gebleken dat wanneer bespuitingen in de buitenste benedenwindse boomrijen van een boomgaard uitgevoerd worden met $90 \%$ driftreducerende spuitdoppen en met aangepaste luchtinstellingen voor naar buiten en naar binnen het perceel tegen de wind spuiten de drift aanzienlijk wordt verlaagd. Dit is zowel bij meerrijen spuiten als bij enkelrij toepassingen gebleken. Bovendien kan met deze toepassingen de buitenste bomenrij van beide zijden bespoten worden. Naar verwachting zal ook de Lochmann dwarsstroomspuit uitgerust met $90 \%$ driftreducerende spuitdoppen (DRD90) en Air Closing System, waarbij separaat de luchtstroom links en rechts op de spuit geregeld kan worden, een hoge driftreductie geven. Om deze verwachting te toetsen en onderbouwen is door WUR in samenwerking met Van der Linden Fruitteelt Machines driftonderzoek uitgevoerd. In het veldonderzoek werd een vergelijking gemaakt tussen de spuitdrift van de Lochmann dwarsstroom boomgaardspuit met lage luchtinstelling, 300 rpm aftakas en uitgerust met het Air Closing System en 90\% driftreducerende doppen (Albuz TVI8001, 7 bar; DRD90) en een standaard dwarsstroom boomgaardspuit (Munckhof met Albuz ATR Lila doppen). De driftmetingen werden dusdanig opgezet dat de resultaten voldoen aan de opgestelde eisen vanuit de toelating van gewasbeschermingsmiddelen ( $\mathrm{Ctgb}$ ), het Activiteitenbesluit Milieubeheer en internationale afspraken rondom meten en classificeren van drift (ISO22866, ISO22369).

De driftmetingen werden uitgevoerd door de buitenste $24 \mathrm{~m}$ ( 8 boomrijen) aan de benedenwindse zijde van een appelboomgaard in het volblad stadium (BBCH 90/92) te bespuiten met de fluorescerende tracer Acid Yellow 250. De driftdepositie werd op een gemaaide grasstrook gemeten naast het bespoten perceel tot op $25 \mathrm{~m}$ afstand vanaf de buitenste bomenrij. De gebruikte collectoren waren filterdoeken (Technofil TF-290) van 0,50x0,10 m die aaneengesloten lagen van $3 \mathrm{~m}$ tot $15 \mathrm{~m}$ en filterdoeken van 1,00x0,10 m op $20 \mathrm{~m}$ en $25 \mathrm{~m}$ van de laatste bomenrij. De drift naar de lucht werd gemeten op 7,5 $\mathrm{m}$ van de laatste bomenrij met behulp van een mast tot $10 \mathrm{~m}$ hoogte met op elke meter hoogte een driftbolcollector (Siral Abdriftkollektoren).

Bij driftmetingen tijdens bespuitingen van een appelboomgaard in het volblad stadium (BBCH 90/92) met de Lochmann dwarsstroom boomgaardspuit met lage luchtinstelling, $300 \mathrm{rpm}$ aftakas en het Air Closing System en TVI8001 spuitdoppen (7 bar; DRD90), waarbij de buitenste drie bomenrijen met luchtinstelling 20\% naar buiten (stand $80 \%$ driftreductie) bespoten werden, werd in vergelijking met een referentie boomgaard bespuiting bij een $3 \mathrm{~m}$ teeltvrije zone op de strook 41/2-51/2 $\mathrm{m}$ vanaf de buitenste bomenrij een driftreductie gevonden van 98,4\%. Op grond van dit resultaat kan de Lochmann dwarsstroom boomgaardspuit met DRD90 spuitdoppen en het Air Closing System ingesteld op $20 \%$ lucht naar buiten in de buitenste 3 bomenrijen in de driftreducerende techniek klasse DRT97,5 ingedeeld worden.

Bij de drift naar de lucht, gemiddeld over 0-10 m hoogte op 7,5 m van de buitenste bomenrij, geeft de Lochmann dwarsstroom boomgaardspuit met DRD90 spuitdoppen, lage luchtinstelling, 300 rpm aftakas en het Air Closing System ingesteld op 20\% lucht naar buiten in de buitenste 3 bomenrijen een driftreductie van $97,0 \%$. 


\section{Summary}

With the Lochmann cross-flow fan orchard sprayer and Air Closing System Wageningen UR performed spray drift experiments following the Dutch TCT and ISO22866 protocols. Measurements were done in comparison with a reference spray technique (Munckhof cross-flow fan sprayer with Albuz ATR lilac nozzles at 7 bar spray pressure). Spray drift experiments were done in the 2018 growing season (August - November 2018) spraying the downwind 8 rows of an apple orchard. Applications were done in the full leaf stage of the apples (BBCH90-92). The Lochmann cross-flow fan orchard sprayer was equipped with $90 \%$ drift reducing nozzles (Albuz TVI8001 at 7 bar spray pressure; DRN90) and the air assistance was set in a low setting using and PTO was set to $300 \mathrm{rpm}$. The Air Closing System was used to adapt air settings in the outer three rows to $80 \%$ air reduction towards the outside of the orchard and full air to the inside of the orchard.

Earlier spray drift experiments showed that using low and variable air settings applied in the outside tree rows of the orchard results in high levels of spray drift reduction. It is therefore expected that also the Lochmann cross-flow fan orchard sprayer with Air Closing System may achieve high levels of spray drift reduction. To assess and underpin this expectation WUR performed spray drift field experiments in cooperation with Van der Linden Fruitteelt Machines.

During the spray drift experiments the downwind outside $24 \mathrm{~m}$ of an apple orchard was sprayed at the full leaf stage (BBCH 90/92) using the fluorescent tracer Acid Yellow 250. Spray drift deposition was collected downwind on a mowed grass area up till $25 \mathrm{~m}$ distance from the last tree row. Filter collectors were used (Technofil TF-290) on ground surface of sizes $0.50 \times 0.10 \mathrm{~m}$ in a continuous row from $3 \mathrm{~m}$ to $15 \mathrm{~m}$ and of $1.00 \times 0.10 \mathrm{~m}$ at $20 \mathrm{~m}$ and $25 \mathrm{~m}$ distance from the last tree row. Airborne spray drift was measured at $7.5 \mathrm{~m}$ distance from the last tree row on a pole at which two lines with collectors (Siral Abdriftkollektoren) were attached at $1 \mathrm{~m}$ spacing up to $10 \mathrm{~m}$ height.

The spray drift experiments showed that spraying an apple orchard at the full leaf stage (BBCH 90/92) with a Lochmann cross-flow fan orchard sprayer fitted with $90 \%$ drift reducing nozzles (Albuz TVI8001; 7 bar spray pressure, DRN90), low air setting, 300 rpm PTO and the Air Closing System set to $20 \%$ air amount towards the outside of the orchard in the outside three tree rows spray drift reduction at 4.5-5.5 m distance from the last tree row was 98.4\% in comparison with the reference spray application. Based on these results this combination can be classified as a spray Drift Reducing Technology (DRT) in the $97.5 \%$ reduction class.

Airborne spray drift reduction at $7.5 \mathrm{~m}$ distance from the last tree row averaged over $10 \mathrm{~m}$ height was for the Lochmann cross-flow fan orchard sprayer fitted with $90 \%$ drift reducing nozzles (Albuz TVI8001; 7 bar spray pressure, DRN90), low air setting, 300 rpm PTO and the Air Closing System set to $20 \%$ air amount towards the outside of the orchard in the outside three tree rows $97.0 \%$. 


\section{$1 \quad$ Inleiding}

De emissie van gewasbeschermingsmiddelen verminderen is van groot belang voor de fruitteelt (VW et al., 2007) en speelt een belangrijke rol bij de invulling van Duurzame Gewasbescherming (EZ, 2013), het Activiteitenbesluit Milieubeheer (I\&W, 2017) en de toelating van gewasbeschermingsmiddelen (Ctgb, 2018). Doel van de Nota Duurzame Gewasbescherming (EZ, 2013) is verminderen van de overschrijding van de milieukwaliteitsnormen voor gewasbeschermingsmiddelen in oppervlaktewater tot nagenoeg nul. Hierbij moet het aantal overschrijdingen van de milieukwaliteitsnormen voor gewasbeschermingsmiddelen in oppervlaktewater in 2023 met 90\% afgenomen zijn ten opzichte van die in 2013. Om dit te realiseren moet op alle percelen de toediening van gewasbeschermingsmiddelen met minimaal 75\% driftreducerende technieken (DRT) uitgevoerd worden. Hierbij stelt het Activiteitenbesluit Milieubeheer (I\&W, 2017) dat voor de fruitteelt de teelvrije zone bij een DRT75 minimaal 4,5 m moet zijn. Als een $3 \mathrm{~m}$ teelvrije teeltvrije zone gebruikt wordt moeten gewasbeschermingsmiddelen met een minimaal 90\% driftreducerende techniek (DRT90) uitgevoerd worden. Daarnaast is ook bij de toelating van gewasbeschermingsmiddelen de driftdepositie op wateroppervlak van belang. Het College voor de Toelating van Bestrijdingsmiddelen en Biociden (Ctgb) neemt beslissingen, onder andere op basis van de inschatting van de effecten op het milieu (Ctgb, 2018). Hierbij is het nodig te weten hoeveel van het middel in het oppervlaktewater terecht komt. Het Ctgb heeft de resultaten van emissie-onderzoek (Zande et al., 2018) ingedeeld naar driftreducerende techniek klassen (DRT) opgenomen in een drifttabel (Ctgb, 2018). In tabel 1.1 is voor de DRT-klassen DRT75 tot DRT99 zoals gebruikt in de fruitteelt voor de kale boom situatie (voor 1 mei) en de volblad situatie (na 1 mei tot 50\% bladval) in driftdepositie weergegeven bij een teeltvrije zone van $3 \mathrm{~m}$.

Tabel 1.1 Driftdepositie (\% van uitgebracht spuitvolume per oppervlakte eenheid) op wateroppervlak (3 m teeltvrije zone, 4,5-5,5 $\mathrm{m}$ vanaf buitenste bomenrij) van driftreducerende technieken (DRT) in verschillende klassen in de kale boom (voor 1 mei) en de volblad (na 1 mei) situatie (naar: Ctgb, 2018).

\begin{tabular}{lrr} 
Driftreducerende techniek groot fruit & Driftpercentage [\%] & kaal volblad \\
\cline { 2 - 3 } Standaard & 16,6 & 8,6 \\
\hline DRT75: & 2,0 \\
\hline DRT90: & 1,0 \\
\hline DRT95: & 2,5 & 1,3 \\
\hline DRT97,5: & 1,3 & 0,36 \\
\hline DRT99: & 0,13 & 0,3 \\
\hline
\end{tabular}

De emissie van gewasbeschermingsmiddelen in de fruitteelt is hoog ten opzichte van andere teeltsectoren. Dit wordt onder meer veroorzaakt door de opgaande en horizontale spuitrichting en de vaak krachtige luchtondersteuning bij fruitteeltspuiten waardoor veel spuitvloeistof door het bladerdek van de bomenrijen heen gespoten wordt. Om drift te beperken zijn verschillende techniek- en teeltmaatregelen mogelijk. Technische maatregelen kunnen bestaan uit doptype, afscherming en luchtondersteuning. Een teeltmaatregel is bijvoorbeeld het aanleggen van een windsingel (windhaag), of het aanleggen van een teeltvrije zone waardoor de afstand tussen het te bespuiten gewas en het oppervlaktewater vergroot wordt, en de drift naar het wateroppervlak af zal nemen. Emissie naar de lucht (druppels en damp) bij gewasbespuitingen wordt in de toelating van middelen of het Activiteitenbesluit Milieubeheer momenteel niet in ogenschouw genomen. Uit metingen is gebleken dat bespuitingen met neveldoppen een aanzienlijke drift naar de lucht tot gevolg kunnen hebben (Michielsen et al., 2007, Zande et al., 2014). Deze emissie kan relevant zijn voor milieubelasting op grotere afstand van percelen, of consequenties hebben voor de aanwezigheid van bijvoorbeeld omwonenden en bebouwing (Gezondheidsraad, 2014). 
Door fruittelers is aangegeven dat het eenzijdig spuiten van de buitenste bomenrij bezwaren heeft in verband met de effectiviteit van de middelen en de bladbedekking van de bespuiting. Men geeft de voorkeur aan de buitenste bomenrij van twee zijden te bespuiten. Door gebruik te maken van $90 \%$ driftreducerende spuitdoppen verlaagde luchthoeveelheid en aanpassing van de luchtrichting afhankelijk van de heersende windrichting is voor 3-rijen spuiten (Stallinga et al., 2013, 2018; Wenneker et al., 2014) en enkelrij boomgaardspuiten (Stallinga et al., 2016, 2017) aangetoond dat dit kan. Van der Linden Fruitteelt Machines (Dreumel) heeft daarom een enkelrij dwarsstroom spuit ontwikkeld, de Lochmann met Air Closing System waarmee afhankelijk van de windrichting het niveau van de luchtondersteuning links en rechts aanpast. Het principe van dit systeem is dat er tegen de wind in meer luchtondersteuning gegeven wordt en met de wind mee minder luchtondersteuning. Door de Lochmann dwarsstroom boomgaardspuit met Air Closing System uit te rusten met $90 \%$ driftreducerende spuitdoppen en gebruik te maken van een lage luchthoeveelheid instelling bij 300 aftakastoerental wordt verwacht dat de driftreductie 97,5\% kan zijn terwijl de buitenste bomenrij wel van twee zijden bespoten wordt. Om de verwachte hoge driftreductie van de Lochmann dwarsstroomspuit met TVI8001 spuitdoppen (DRD90), lage luchtinstelling, 300 rpm aftakas toeren en met het Air Closing System 80\% dichte luchtklepinstelling van de naar buiten gerichte lucht in de buitenste 3 bomenrijen te onderbouwen is dit driftonderzoek in opdracht van Van der Linden Fruitteelt Machines (Dreumel) uitgevoerd.

\section{Doel van het onderzoek}

Het doel van het onderzoek is de vergelijking van de spuitdrift van de Lochmann dwarsstroomspuit met TVI8001 spuitdoppen (DRD90), lage luchtinstelling, 300 rpm aftakas toeren en met het Air Closing System 80\% dichte luchtklepinstelling van de naar buiten gerichte lucht in de buitenste 3 bomenrijen en een standaard dwarsstroom boomgaardspuit (met ATR Lila spuitdoppen). De driftmetingen werden dusdanig opgezet dat de resultaten voldoen aan de opgestelde eisen vanuit de toelating van gewasbeschermingsmiddelen (Ctgb), het Activiteitenbesluit Milieubeheer (I\&W, 2017) en internationale afspraken rondom erkenning van driftmetingen (ISO22866, 2005; ISO22369, 2006). In deze rapportage worden de uitgevoerde driftmetingen van de Lochmann dwarsstroomspuit met Air Closing System en de standaard dwarsstroom boomgaardspuit (Huijsmans et al., 1997) tijdens bespuitingen van een appelboomgaard in het volblad (na 1 mei) stadium beschreven. In hoofdstuk 2 wordt de proefopzet besproken, daarna volgen in hoofdstuk 3, 4 en 5 respectievelijk de resultaten, discussie en conclusies. 


\section{Materiaal en Methode}

\subsection{Afstelling en beschrijving spuittechniek}

In een veldonderzoek is in 2018 de drift vastgelegd van een Lochman dwarsstroomspuit met Air Closing System (Lochmann Plantatec, Nals Italië), in Nederland vertegenwoordigd door Van der Linden Fruitteelt Machines te Dreumel. De driftmetingen zijn uitgevoerd met een Albuz TVI8001 spuitdop bij 7 bar spuitdruk (90\% driftreducerend; DRD90, TCT, 2018b) en bij 300 rpm aftakas toerental, om een lager niveau van luchthoeveelheid te realiseren. Het Air Closing System zorgt ervoor dat bij de bespuiting van de buitenste drie bomenrijen de lucht naar de buitenkant van het perceel (met de wind mee) $80 \%$ lager is dan de lucht naar het perceel toe (tegen de wind in).

De drift van de Lochman dwarsstroomspuit werd vergeleken met die van de Munckhof dwarsstroomspuit voorzien van Albuz ATR Lila doppen (referentietechniek; TCT, 2017b). In paragraaf 2.1.1 staan karakteristieken beschreven van de in de proeven gebruikte Munckhof dwarsstroomspuit en in paragraaf 2.1.2 staat een beschrijving van de Lochmann dwarsstroomspuit. In paragraaf 2.1.3 staat een samenvattend overzicht van de gebruikte spuittechnieken.

\subsubsection{Karakteristieken Munckhof dwarsstroomspuit}

De Munckhof dwarsstroomspuit (Munckhof, Horst) is een axiaalspuit voorzien van een dwarsstroomkap op de ventilator (figuur 2.1).

In tabel 2.1 staan de posities van de dophouders van de Munckhof dwarsstroomspuit boven grondoppervlak weergegeven.

Tabel 2.1 Dophoogte vanaf de grond [cm] van de dophouders op de Munckhof dwarsstroomspuit.

\begin{tabular}{lrrrrrrrrrrr} 
dopnr & 1 & 2 & 3 & 4 & 5 & 6 & 7 & 8 & 9 \\
links & 50 & 68 & 84 & 99 & 120 & 153 & 180 & 215 & 250 & 285 \\
\hline rechts & 48 & 66 & 81 & 99 & 121 & 153 & 181 & 216 & 251 & 286 \\
\hline
\end{tabular}

Er werd gespoten met $2 \times 8$ geopende spuitdoppen, waarbij de onderste $(50 \mathrm{~cm})$ en de bovenste dop (op $285 \mathrm{~cm}$ ) waren gesloten. De bovenste spuitende dop zat op 2,50 $\mathrm{m}$ hoogte in overeenstemming met de toppen van de fruitbomen. De spuit werd aangedreven door een New Holland T4050N fruitteelt trekker, met een rijsnelheid van $6,7 \mathrm{~km} / \mathrm{h}$ en een aftakas toerental van $540 \mathrm{rpm}$.

Er werd gemeten bij de vollucht stand van de ventilator, hierbij was de gemiddelde luchtsnelheid over de gehele luchtspleet $21 \mathrm{~m} / \mathrm{s}$. Bij de bespuitingen werd de drift vastgelegd bij gebruik van Albuz ATR Lila werveldoppen en een druk van 7 bar (referentie) en een spuitvolume van $226 \mathrm{l} / \mathrm{ha}$.

\subsubsection{Lochmann dwarsstroomspuit}

In tabel 2.2 staan de posities van de dophouders op de Lochmann dwarsstroomspuit boven grondoppervlak weergegeven.

Tabel 2.2 Dophoogte vanaf de grond [cm] van de dophouders links en rechts van de Lochman dwarsstroomspuit.

\begin{tabular}{lrrrrrrrrr} 
dopnr & 1 & 2 & 3 & 4 & 5 & 6 & 7 & 8 & 9 \\
links & 72 & 96 & 121 & 144 & 169 & 192 & 216 & 240 & 265 \\
\hline rechts & 70 & 95 & 119 & 143 & 167 & 191 & 215 & 240 & 264 \\
\hline
\end{tabular}




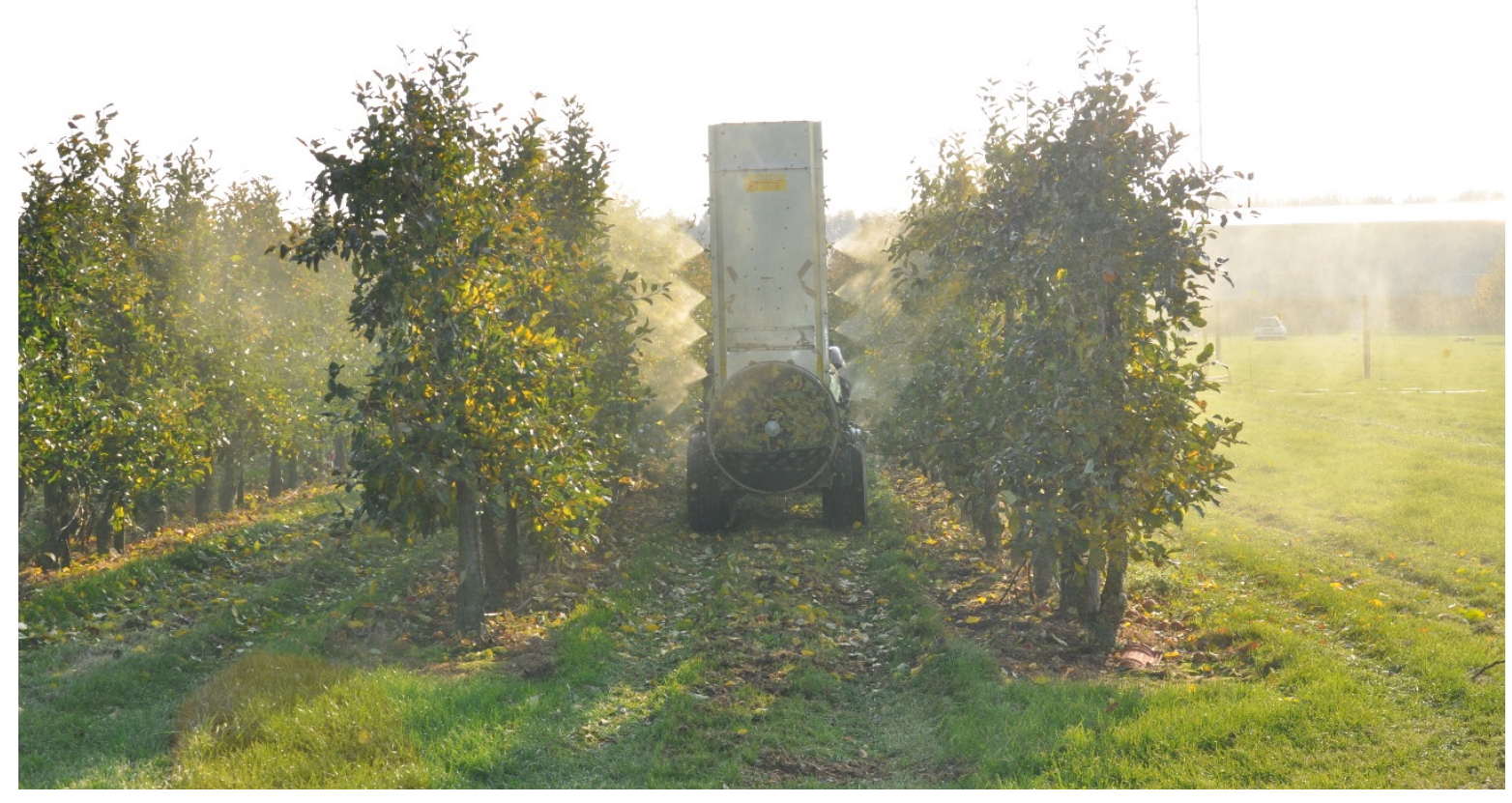

Figuur 2.1 Standaard dwarsstroomspuit (Munckhof) tijdens driftmetingen.

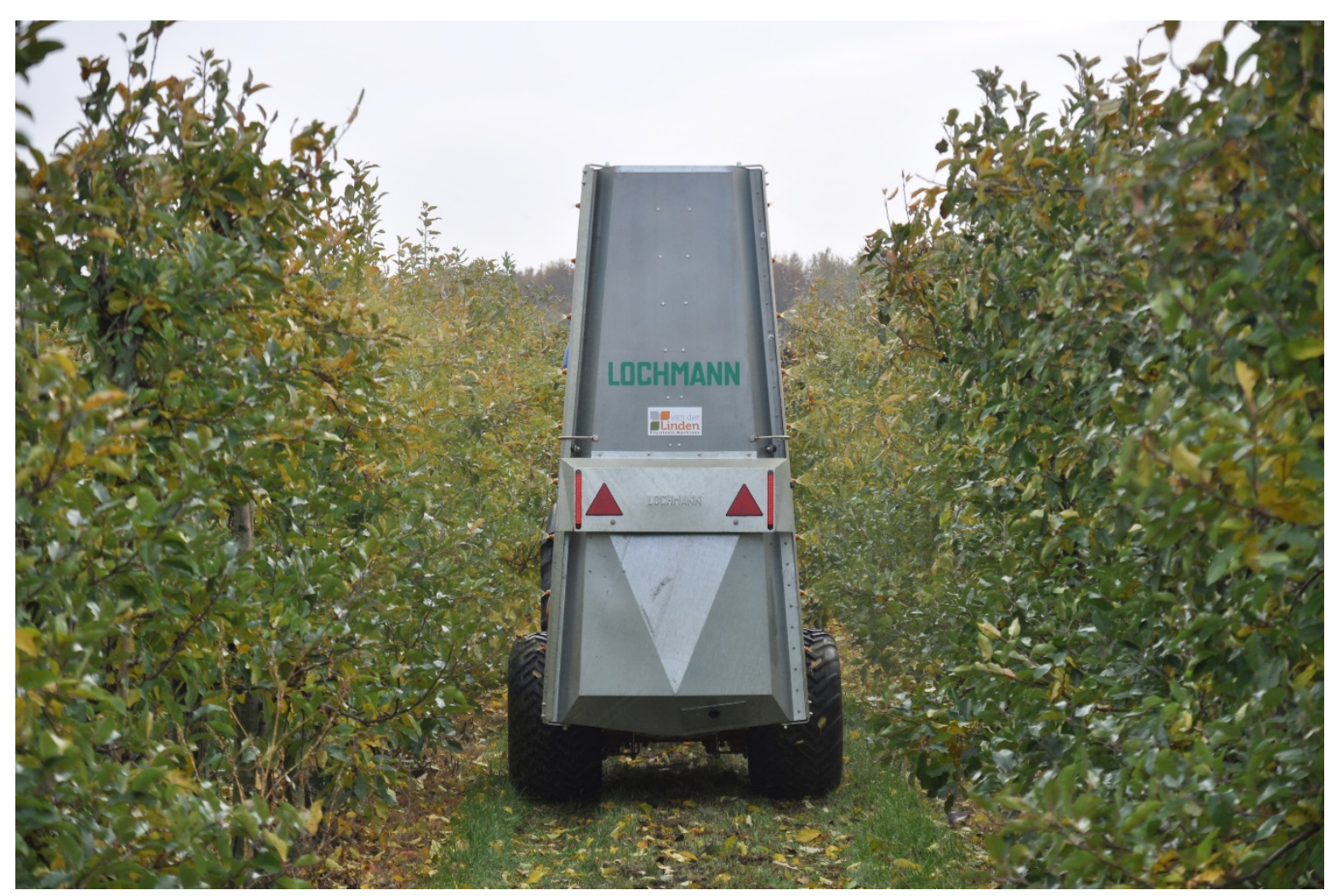

Figuur 2.2 Lochmann dwarsstroomspuit met Air Closing System tijdens driftmetingen. 
Tijdens de driftmetingen (figuur 2.2) werd er gespoten met alle spuitdoppen geopende (2x9). De bovenste spuitende dop zat op 2,65 m hoogte in overeenstemming met de toppen van de fruitbomen. De spuit werd getrokken door een New Holland T4050N fruitteelt trekker. De rijsnelheid bij een aftakastoerental van $300 \mathrm{rpm}$ was $6,0 \mathrm{~km} / \mathrm{h}$. Bij de bespuitingen werd de drift vastgelegd bij gebruik van Albuz TVI8001 spuitdop bij 7 bar spuitdruk (figuur 2.6, DRD90, TCT, 2018b). Het spuitvolume was 372 I/ha.

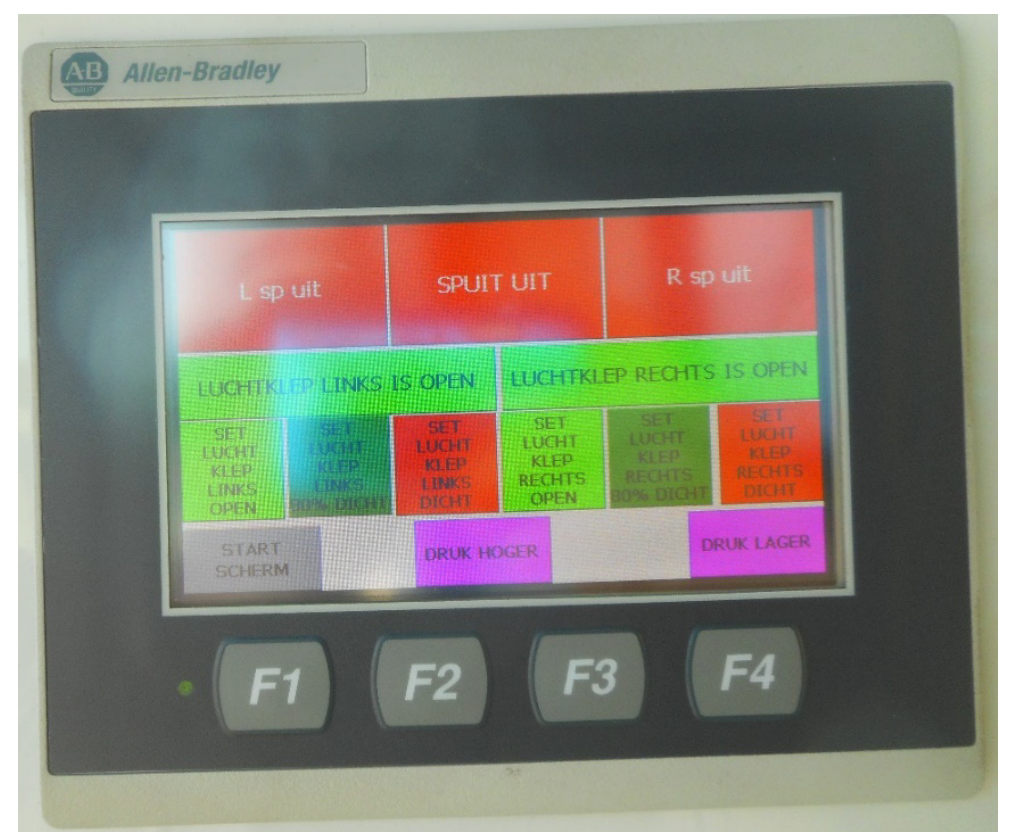

Figuur 2.3 Scherm van spuitcomputer met daarop per spuitrichting (links/rechts) een drukknop voor de bediening van de luchtklepinstelling OPEN (licht groen), 80\% DICHT (donker groen), DICHT (rood).

De Lochmann dwarsstroomspuit heeft de mogelijkheid links en rechts met een klep de hoeveelheid van de luchtondersteuning te regelen. Op de spuitcomputer (figuur 2.3) kan aangegeven worden of de klep voor de luchtuitstroomopening helemaal open moet staan (OPEN), helemaal dicht (DICHT) of voor $80 \%$ afgesloten ( $80 \%$ DICHT). Dit systeem van variabele luchthoeveelheid is het Air Closing System genoemd. Tijdens de driftmetingen is bij de bespuiting aan de buitenkant van de buitenste bomenrij de luchtondersteuning en de spuitdoppen richting buiten het perceel aan de buitenkant van de buitenste bomenrij afgesloten (figuur 2.3, 2.4, 2.5). Alle bomenrijen werden tweezijdig bespoten waarbij bij de buitenste 3 bomenrijen de luchthoeveelheid naar buiten het perceel toe steeds maar $20 \%$ van de capaciteit was (klep aan die zijde $80 \%$ dicht). Naar binnen toe werd tegen de windrichting in steeds met vollucht (100\%, klep open) gespoten.
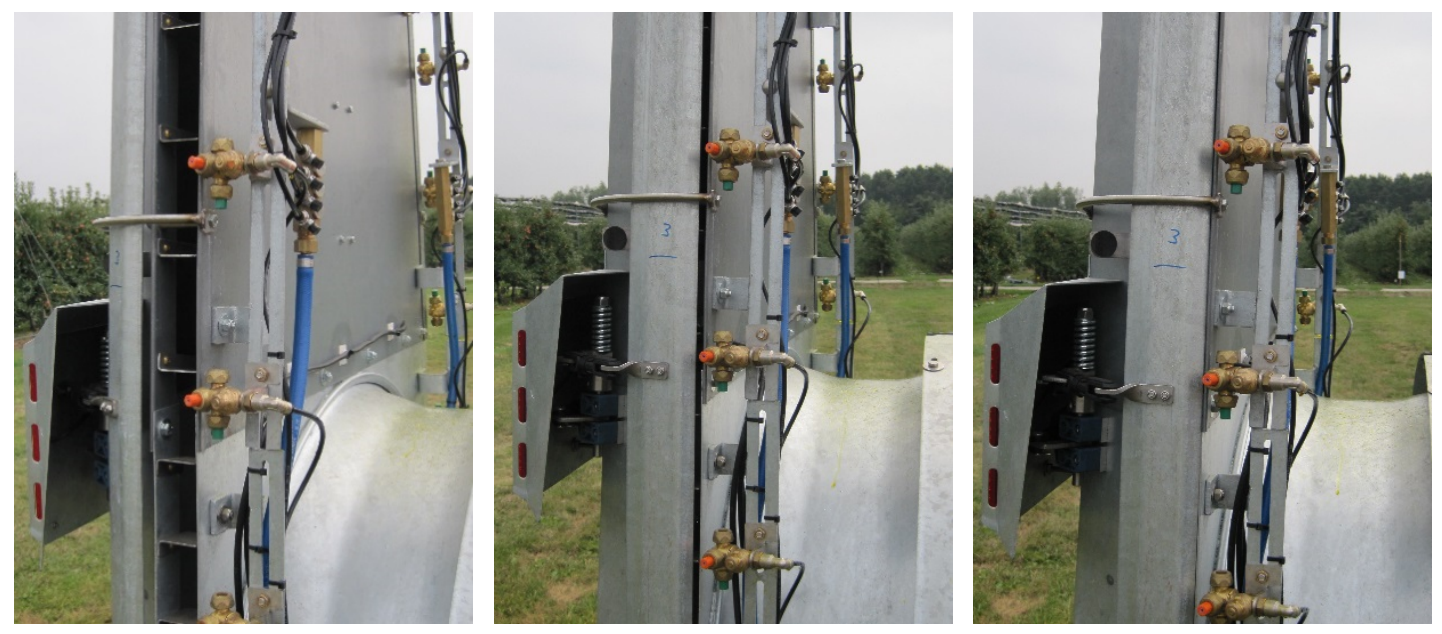

Figuur 2.4 Klepstanden van het Air Closing System op de Lochmann dwarsstroom boomgaardspuit bij de luchtklepinstelling OPEN (links), 80\% DICHT (midden), DICHT (rechts). 


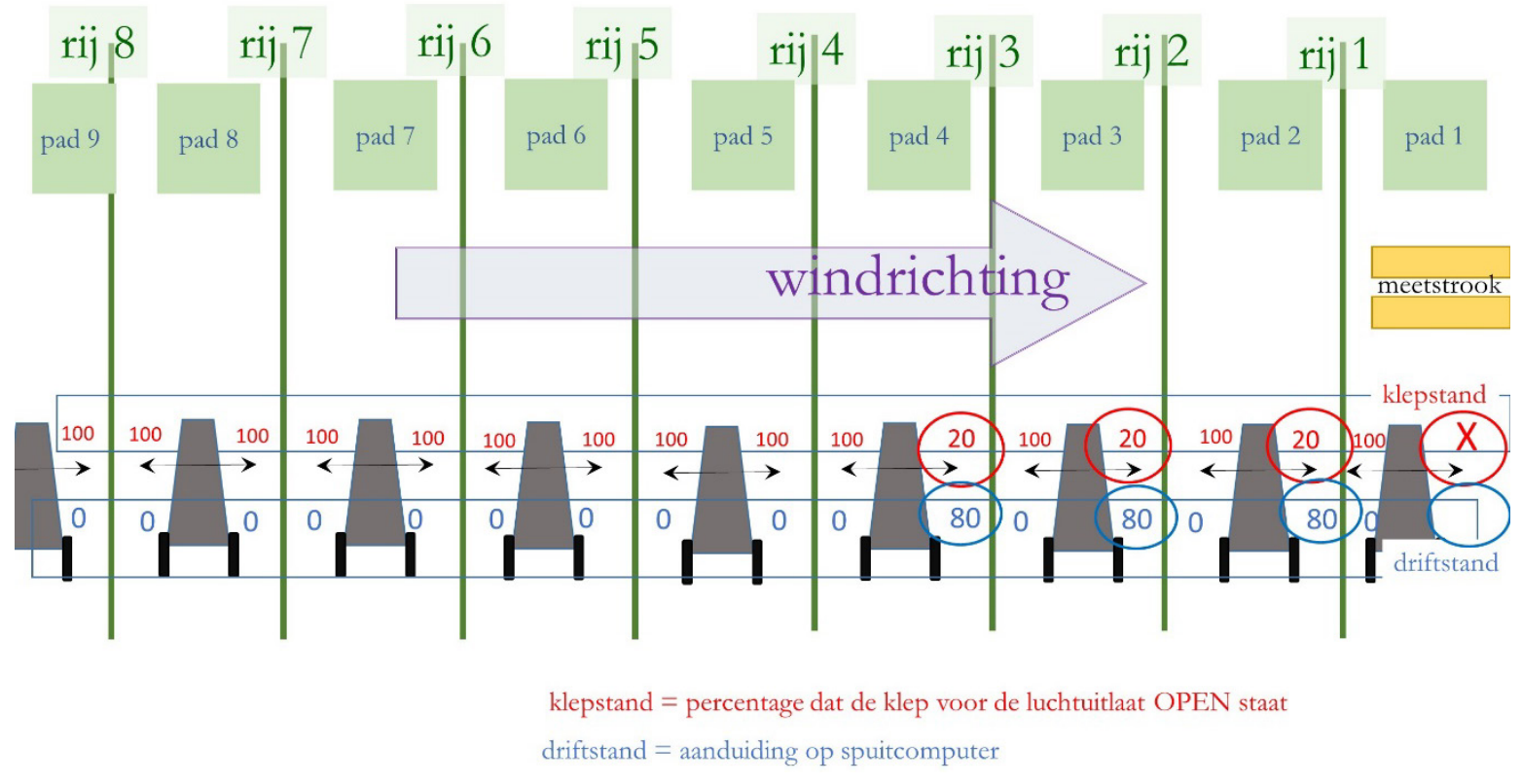

Figuur 2.5 Klepstanden van het Air Closing System op de Lochmann dwarsstroomspuit tijdens de driftmetingen (20=20\% luchtcapaciteit $=$ klep $80 \%$ dicht $)$.

Tijdens de driftmetingen stond de overbrengingsverhouding van de ventilator op de Lochmann dwarsstroom boomgaardspuit op de stand 1:3 (figuur 2.6), wat een lage luchtopbrengst geeft. Hierdoor was bij deze instelling en $300 \mathrm{rpm}$ van de aftakas de uittreesnelheid van de lucht bij de uitstroomopening gemiddeld $9,5 \mathrm{~m} / \mathrm{s}$.
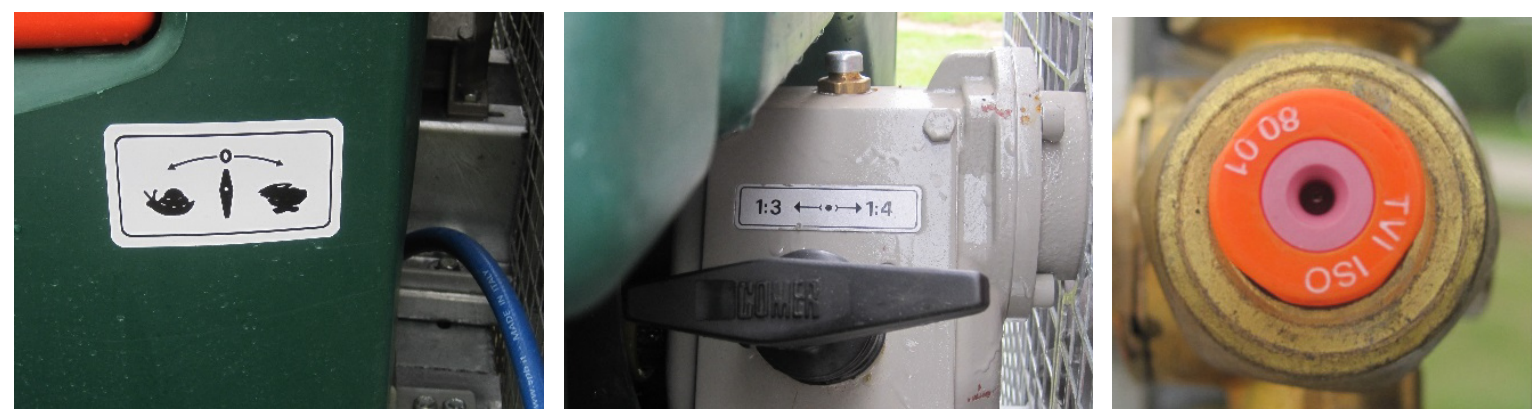

Figuur 2.6 Stand van de overbrengingsverhouding van de ventilator op de Lochmann dwarsstroom boomgaardspuit (links, indicatie op tank, midden, stand handgreep) en de gebruikt Albuz TVI 8001 spuitdop (rechts).

\subsubsection{Samenvatting gebruikte spuittechnieken}

In tabel 2.3 staat een samenvatting van de tijdens de driftmetingen gebruikte spuittechnieken.

Tabel 2.3 Samenvatting gebruikte spuittechnieken in de driftmetingen

\begin{tabular}{lcc} 
Spuit & Munckhof dwarsstroom & Lochmann dwarsstroomspuit \\
\hline aftakas & 540 & 300 \\
\hline Spuitdoppen & Albuz & Albuz \\
\hline doptype & ATR Lila & TVI8001 \\
\hline druk [bar] & Werveldop & Venturi werveldop \\
\hline $\mathrm{n}$-doppen & 7 & 7 \\
\hline dop afgifte $[\mathrm{l} / \mathrm{min}]$ & $2 \times 8$ & $2 \times 9$ \\
\hline Gemiddelde rijsnelheid $[\mathrm{km} / \mathrm{h}]$ & 0,42 & 0,61 \\
\hline Gemiddeld spuitvolume $[\mathrm{l} / \mathrm{ha}]$ & 6,7 & 6,0 \\
\hline
\end{tabular}




\subsection{Beschrijving metingen en verwerking resultaten}

\subsubsection{Metingen}

De experimenten werden op 15 augustus, 23 augustus, 19 oktober, 13 november en

21 november 2018 uitgevoerd op de Proeftuin Randwijk te Randwijk. Op perceel Oost $1 \mathrm{~A}$ werden de driftmetingen in overeenstemming met de driftmeetprotocollen (TCT 2017b, ISO22866) uitgevoerd. Dit perceel is aangeplant met het appelras Elstar. De fruitbomen staan in een plantverband van $1,10 \mathrm{~m}$ afstand in de rij en $3 \mathrm{~m}$ tussen de rijen (rijafstand). De bomen waren 2,75 $\mathrm{m}$ hoog en in het volblad stadium (BBCH 90/92). Het perceel bestond uit een blok van 110 meter lengte en 14 rijen (52 $\mathrm{m}$ ) breed (figuur 2.7). Daaromheen lag een strook gras van ongeveer $30 \mathrm{~m}$ breed. Op deze strook gras werden twee driftmeetstroken uitgelegd (figuur 2.7). Tijdens de driftmetingen werden de laatste acht bomenrijen $(24 \mathrm{~m}$ ) aan de benedenwindse zijde volledig bespoten. Met één en dezelfde instelling werd steeds het blok van acht boomrijen bespoten.

Bij elke driftmeetstrook werden twee meetraaien (duplo bepalingen) uitgelegd met 1 meter tussenruimte tussen de meetraaien. In het meetgedeelte naast het perceel werden 2 herhalingen van de driftmeetstroken achter elkaar gelegd, op een onderlinge afstand van $30 \mathrm{~m}$.

Op de volgende posities werden collectoren (Technofil TF $290 ; 10 \times 100 \mathrm{~cm}, 10 \times 50 \mathrm{~cm}$ ) gelegd om de driftdepositie naar de grond te meten (figuur 2.7, figuur 2.8):

- Op 1,5 meter, evenwijdig aan de buitenste bomenrij, een collector van 1 meter lengte.

- Op 3 - 15 meter aaneengesloten collectoren van 0,5 meter lengte (haaks op de bomenrij).

- Op 20 en 25 meter een collector van 1 meter lengte (haaks op de bomenrij).

De afstand werd gemeten vanaf het midden (hart) van de buitenste bomenrij.

De emissie naar de lucht werd op 7,5 m vanaf de laatste bomenrij met behulp van een mast van $10 \mathrm{~m}$ hoogte gemeten (figuur 2.7, figuur 2.8), met in twee lijnen met ieder op elke meter hoogte een driftbolcollector (Siral Abdriftkollektoren art. nr. 00131).

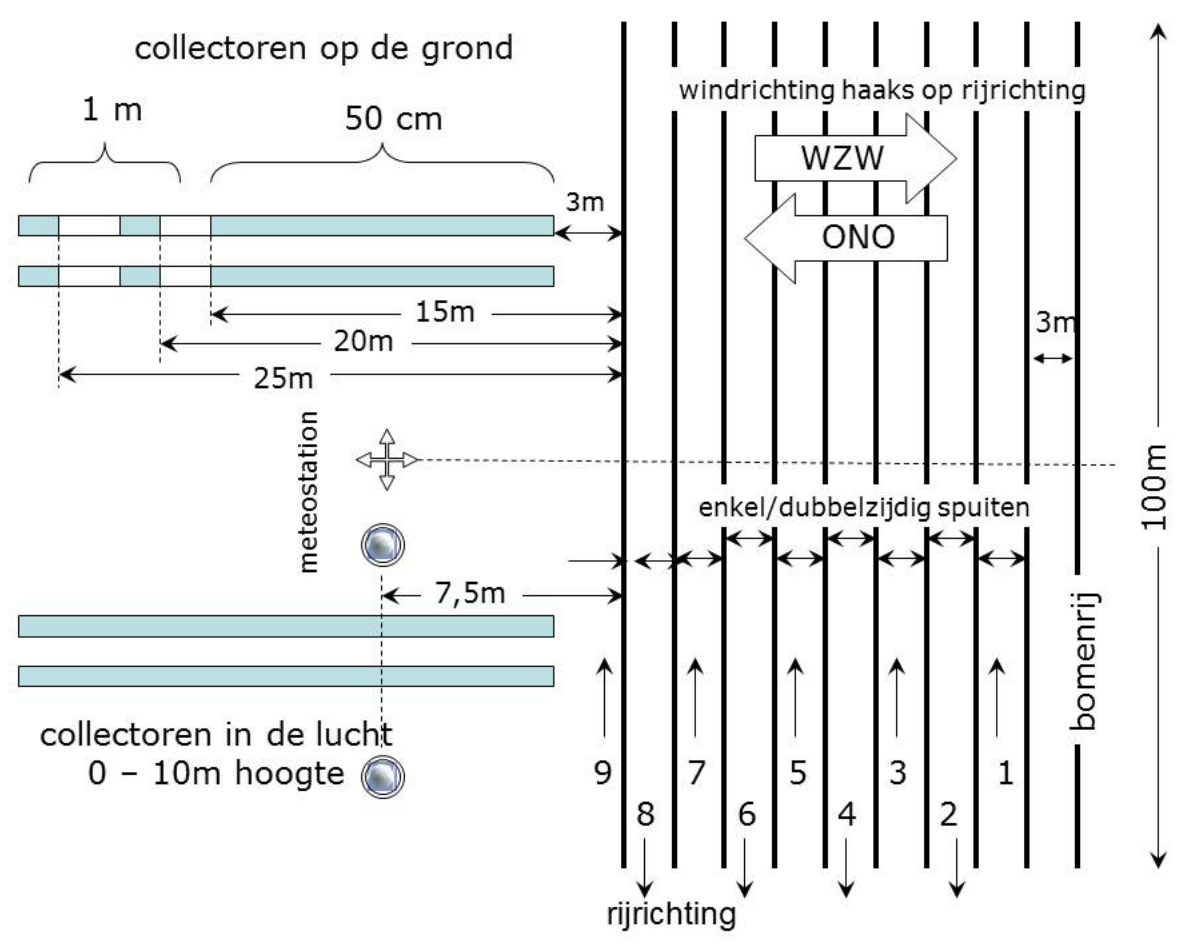

Figuur 2.7 Schematische weergave proefveld en meetopstelling. 


\subsubsection{Analyses}

De bespuitingen werden uitgevoerd met water waaraan Acid Yellow 250 (AY250, DC Finechemicals, CAS nummer 93859-32-6, 2-5 g/l) en een niet-ionische uitvloeier (Agral Gold, 0,075 ml/l) was toegevoegd. Na de bespuiting werden de collectoren verzameld en gecodeerd voor verdere analyse op de hoeveelheid AY250. Elke meetdag werden uit een spuitende spuitdop ook monsters van de tankvloeistof genomen om de AY250-concentratie van de verspoten spuitvloeistof te meten. In het laboratorium werden de collectoren met gedemineraliseerd water gespoeld, zodanig dat de AY250 op de collectoren in oplossing kwam. Van deze oplossing werd de concentratie aan AY250 gemeten met behulp van een fluorimeter (Perkin Elmer LS 55; $\lambda_{\mathrm{ex}}=450 \mathrm{~nm} ; \lambda_{\mathrm{em}}=500 \mathrm{~nm}$ ). Voor het bepalen van de achtergrondfluorescentie werden blanco collectoren geanalyseerd. De concentratie AY250 in de tankmonsters werd ook fluorimetrisch bepaald. De concentratie AY250 in de tankmonsters werd ook fluorimetrisch bepaald. De afbraak in zonlicht van de AY250 op de collectoren werd apart bepaald. Gezien de beperkte blootstellingsduur aan zonlicht van de collectoren tijdens de driftmetingen in het veld ( $<30$ minuten) was het niet nodig voor afbraak door zonlicht te corrigeren.
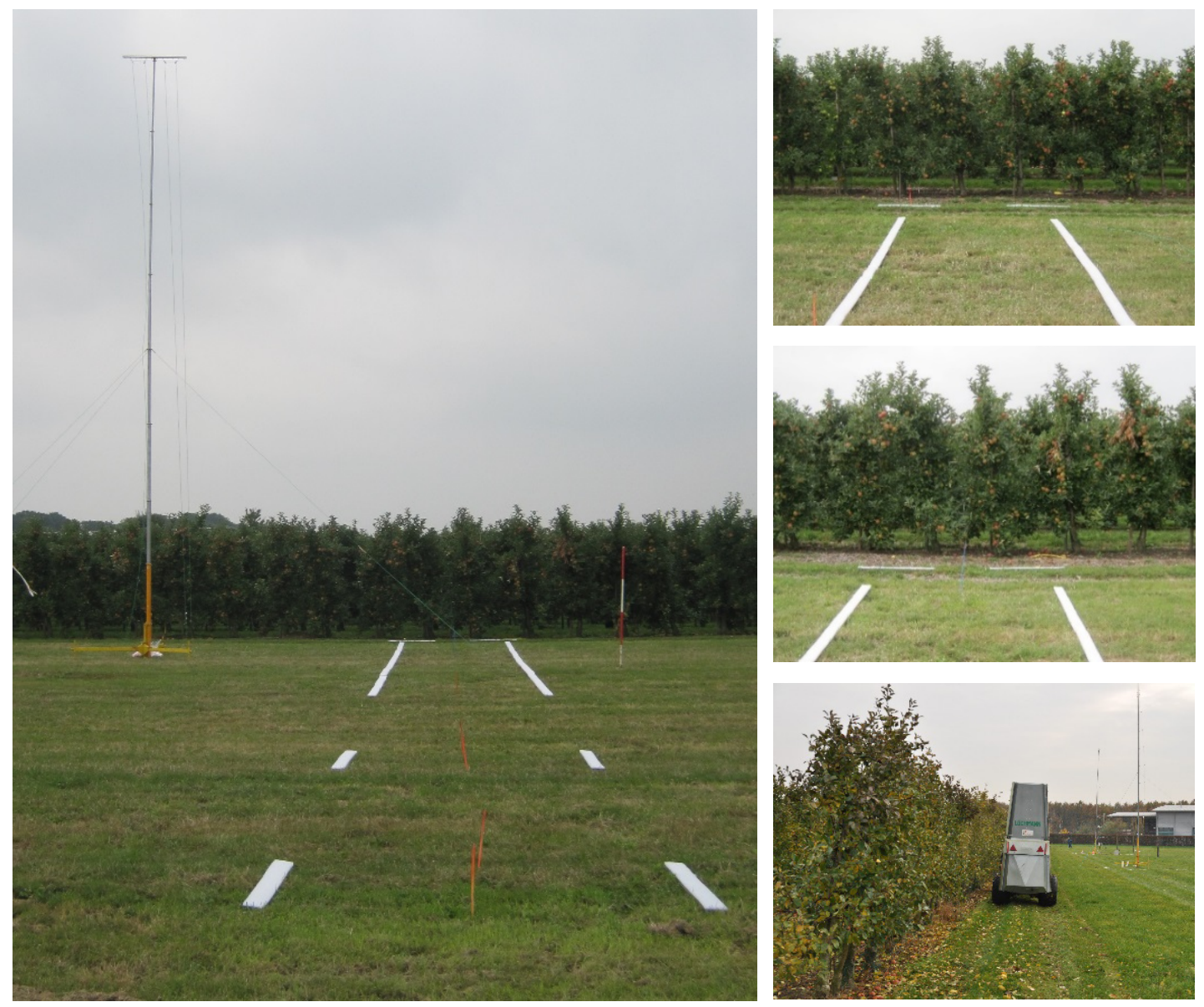

Figuur 2.8 Overzicht drift meetopstelling (links); collectoren op de grond tot $25 \mathrm{~m}$ van de buitenste bomenrij, op 7,5 $\mathrm{m}$ mast voor meten van de luchtdrift tot $10 \mathrm{~m}$ hoog; indruk van bladmassa appelbomen op de verschillende meetdagen en collectoren dicht bij buitenste bomenrij op twee meetplekken (rechts). 


\subsubsection{Berekeningen en statistiek}

De concentratie werd omgerekend naar volume spuitvloeistof per oppervlakte-eenheid. Het percentage drift is berekend door de driftdepositie per oppervlakte-eenheid uit te drukken in procenten van de door de spuitdoppen in het perceel verspoten hoeveelheid vloeistof per oppervlakte-eenheid.

De gemeten fluorescentiewaarde werd omgerekend naar de driftdepositie $\left(\mu \mathrm{l} / \mathrm{cm}^{2}\right)$ volgens:

$$
D_{\text {monster }}=\frac{\left(F_{\text {monster }}-F_{\text {demi }}-F_{\text {blanco }}\right) \times f_{i j k} \times V_{\text {spoel }}}{C_{\text {tm }} \times A_{\text {monster }}}
$$

$\mathrm{D}=$ depositie in $\mu \mathrm{L} / \mathrm{cm}^{2}$;

$\mathrm{F}=$ fluorescentiewaarde $; F_{\text {monster }}=$ fluorescentiewaarde van het monster $; F_{\text {demi }}=$ fluorescentiewaarde van demiwater; $F_{\text {blanco }}=$ bijdrage van de achtergrond door collector;

$\mathrm{f}_{\mathrm{ijk}}=\mathrm{ijkfactor} ; \mathrm{V}_{\text {spoel }}=$ extractievolume in liter;

$\mathrm{C}_{\mathrm{tm}}=$ spuitvloeistofconcentratie in tank in $\mathrm{g} \cdot \mathrm{L}^{-1} ; \mathrm{A}_{\text {monster }}=$ monsteroppervlak in $\mathrm{cm}^{2}$.

Voor de statistische verwerking wordt indien $\left(F_{\text {monster }}-F_{\text {demi }}-F_{\text {blanco }}\right)$ kleiner of gelijk aan 0 is, hier een kleine waarde ingevuld $(0,001)$.

Vervolgens werd per monster de driftdepositie uitgedrukt als percentage van het uitgebracht spuitvolume volgens:

$$
P=\frac{D_{m}}{Q / 100} \times 100 \%
$$

$\mathrm{P}=$ percentage drift van het uitgebrachte spuitvolume; $\mathrm{D}_{\mathrm{m}}=$ driftdepositie in $\mu \mathrm{l} / \mathrm{cm}^{2} ; \mathrm{Q}=$ spuitvolume in L/ha

Voor de vergelijking van de driftdepositie van de verschillende spuittechnieken zijn de driftwaarden (\% van spuitvolume) uitgerekend voor verschillende evaluatiestroken overeenkomend met de positie van de sloot (insteek-insteek afstand $4 \mathrm{~m}$ ) en het wateroppervlak daarbinnen $(1 \mathrm{~m})$. De teeltvrije zone wordt in het Activiteitenbesluit Milieubeheer (I\&W, 2017) gedefinieerd als de afstand tussen de insteek van de sloot en de buitenste gewasrij (voor fruitteelt $3 \mathrm{~m}$ in figuur 2.9). De volgende evaluatiestroken worden onderscheiden:

- slootoppervlak: 3-7, 41/2-81/2, 6-10 en 9-13 m, bij respectievelijk 3, 41/2, 6 en 9 m teeltvrije zone.

- wateroppervlak: 41/2-51/2,6-7, 71/2-81/2,101/2-111/2 m, bij respectievelijk 3, 41/2, 6 en 9 m teeltvrije zone.

- naar de lucht: gemiddeld over $10 \mathrm{~m}$ hoogte op 7,5 m vanaf de laatste bomenrij.

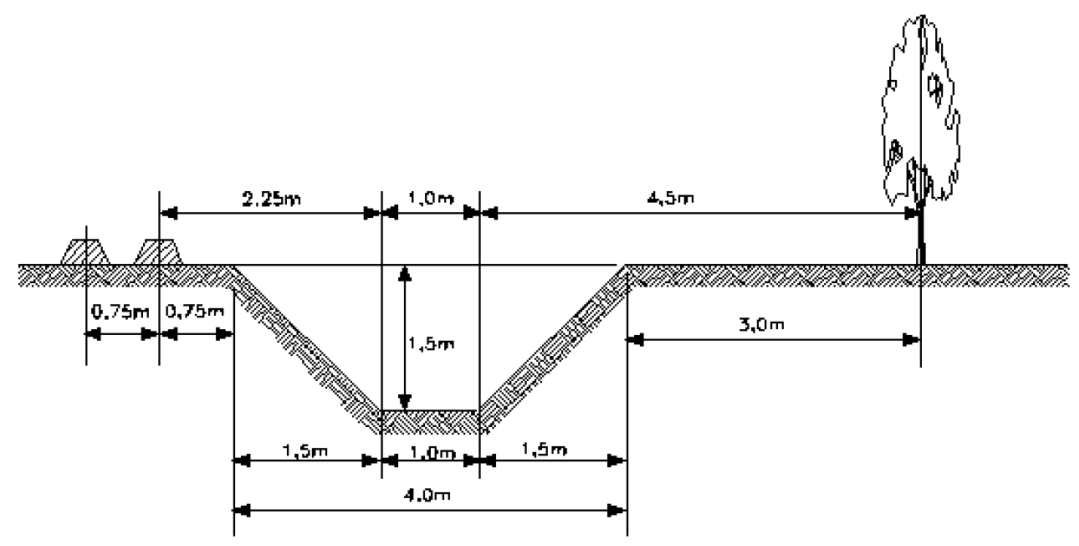

Figuur 2.9 Schematische weergave van de plaats van de sloot, het talud en het wateroppervlak ten opzichte van de laatste gewasrij in aardappelen (links) en de buitenste bomenrij in de fruitteelt (rechts) (Huijsmans et al., 1997). 
De gekozen zones van $3 \mathrm{~m}, 41 \frac{1}{2} \mathrm{~m}, 6 \mathrm{~m}$ en $9 \mathrm{~m}$ komen overeen met de in het Activiteitenbesluit Milieubeheer (I\&W, 2017) genoemde zones. Daarbij is 4,5 $\mathrm{m}$ de teeltvrije zone waarbij een bespuiting nog met een $75 \%$ driftreducerende spuittechniek (DRT75) uitgevoerd mag worden. De zone $3 \mathrm{~m}$ geldt als teeltvrije zone als de bespuiting uitgevoerd wordt met een 90\% driftbeperkende techniek (DRT90). Voor de kopakker geldt een minimale teeltvrije zone van $6 \mathrm{~m}$.

De verschillen in driftdepositiewaarden op de evaluatiestroken tussen de verschillende spuittechnieken werden getoetst bij een onbetrouwbaarheidsdrempel van $5 \%$. Statistische analyse vond plaats met behulp van het statistische programma Genstat (Genstat Release 9.2, Payne et al., 2006). Bij de statistische analyse werd gebruik gemaakt van de Genstat procedure IRREML (Keen en Engel, 1998). In bijlage I staat het gebruikte IRREML script.

Voor de indeling van de Lochmann dwarsstroomspuit voorzien van TVI 8001 spuitdoppen (DRD90), lage luchtinstelling, $300 \mathrm{rpm}$ aftakas toeren, 80\% dichte luchtklepinstelling in de buitenste 3 bomenrijen in driftreductieklassen (ISO22369-1) werd de driftreductie op de gemeten afstanden en de evaluatiestroken berekend ten opzichte van de driftdepositie van de referentie bespuiting met de Munckhof dwarsstroomspuit uitgerust met Albuz ATR Lila doppen volgens:

$\%$ reductie $=\frac{\left(P_{\text {driftref }}-P_{\text {techniek }}\right)}{P_{\text {driftref }}} \times 100 \%$

$\mathrm{P}_{\text {driftref }}=$ Percentage drift referentietechniek en dop (Munckhof dwarsstroom met Albuz ATR Lila spuitdoppen).

$\mathrm{P}_{\text {techniek }}=$ Percentage drift Lochmann dwarsstroomspuit met DRD90 spuitdoppen, (DRD90), lage luchtinstelling, $300 \mathrm{rpm}$ aftakas toeren, $80 \%$ dichte luchtklepinstelling naar buiten gerichte lucht in de buitenste 3 bomenrijen.

De indeling in driftreductieklasse op de strook 4,5-5,5 $\mathrm{m}$ vande laatste bomenrij geldt hierbij als de indeling in Drift Reducerende Techniek (DRT) klasse (TCT2017a, 2017b).

Voor het bepalen van de achtergrondfluorescentie worden blanco collectoren geanalyseerd. Het resultaat van deze metingen is een gemiddelde achtergrondfluorescentie van de blanco collectoren met een bijbehorende standaardafwijking. Bij de berekeningen van de driftdepositie (volgens bovenstaande formules) wordt het gemiddelde van de achtergrondfluorescentie gebruikt. Bij de experimenten werden zeer lage driftdeposities gemeten met fluorescentiewaarden dicht of zelfs onder de gemiddelde achtergrondfluorescentie. Berekende driftdeposities kunnen dan zelfs lager dan 0\% worden. De drempelwaarde, in dit rapport aangehouden, is de gemiddelde fluorescentiewaarde van de blanco plus twee keer de standaardafwijking van de blanco. Deze drempelwaarde is omgerekend naar driftdepositie volgens bovenstaande formules. De drempelwaarde is o.a. afhankelijk van de gemeten techniek (spuitvolume), spoelvolume bij de extractie, collectorgrootte en tankconcentratie en kan per meting (herhaling) verschillen. In de bijlagen staan de berekende waarden, ook die onder de drempelwaarde vallen. Getallen die onder de bijbehorende drempelwaarde vallen staan cursief. Als er in het rapport zelf getallen gepresenteerd worden (bv in samenvattende tabel met de afstand) waarbij de gemiddelde gemeten waarde onder de drempelwaarde komt dan wordt dat aangeven met '<drempelwaarde'. Bijvoorbeeld '<0,006'.

\subsection{Weersomstandigheden}

Tijdens de bespuitingen werden de weersomstandigheden vastgelegd door meting van de temperatuur (Pt100 op 0,5 m en 4 m hoogte), de luchtvochtigheid (\% RV met een Rhotronic op 1,5 m hoogte), de windrichting $\left(0^{0}=\right.$ haaks t.o.v. de bomenrijen) op $10 \mathrm{~m}$ hoogte en de windsnelheid (cupanemometers op 0,5, 2, 3, 4 en $10 \mathrm{~m}$ hoogte) met een tijdsinterval van 5 seconden. 
De meteomast stond op 7,5 m afstand vanaf de buitenste bomenrij (figuur 2.7). Bij elke passage van de spuit ter hoogte de meetopstellingen werd de tijd van de datalogger genoteerd. Later werd uit de verzamelde data vanuit dit passagetijdstip over 10 seconden vóór en 10 seconden ná passeertijdstip de meetwaarde gemiddeld. In Bijlage II staan de resultaten van de metingen van de weersomstandigheden vermeld.

De metingen werden in 2018 uitgevoerd op 15 augustus, 23 augustus, 19 oktober, 13 november en 21 november. In totaal werden 10 herhalingen gemeten. Bij 2 herhalingen van de Standaard $(1+2)$ was de gemiddelde windhoek $>30^{\circ}$ van haaks. Deze metingen zijn niet verwerkt in de resultaten. De gemiddelde weersomstandigheden van de metingen staan in tabel 2.4 .

Tabel 2.4 Gemiddelde weersomstandigheden voor de verschillende technieken tijdens de driftmetingen.

\begin{tabular}{|c|c|c|c|c|c|c|c|c|c|}
\hline \multirow[t]{2}{*}{ Techniek } & \multicolumn{2}{|c|}{$\begin{array}{c}\text { Temperatuur }\left[{ }^{\circ} \mathrm{C}\right] \\
\text { op } \\
\end{array}$} & \multirow[t]{2}{*}{$\%$ RV } & \multirow{2}{*}{$\begin{array}{l}\text { Windhoek } \\
\text { tov haaks } \\
\text { haaks }=0^{\circ}\end{array}$} & \multicolumn{5}{|c|}{ Windsnelheid $[\mathrm{m} / \mathrm{s}]$ op } \\
\hline & $0,5 \mathrm{~m}$ & $4 \mathrm{~m}$ & & & $0,5 \mathrm{~m}$ & $2 \mathrm{~m}$ & $3 \mathrm{~m}$ & $4 \mathrm{~m}$ & $10 \mathrm{~m}$ \\
\hline $\begin{array}{l}\text { Lochmann } \\
\text { dwarsstroomspuit }\end{array}$ & 10,0 & 9,1 & 68 & 1 & 1,1 & 1,7 & 2,4 & 2,8 & 4,3 \\
\hline
\end{tabular}

Tijdens de driftmetingen was de gemiddelde temperatuur $11,4^{\circ} \mathrm{C}$ (op $4 \mathrm{~m}$ hoogte), de gemiddelde windhoek $1^{\circ}$ ten opzichte van loodrecht op de bomenrij en de gemiddelde windsnelheid op $2 \mathrm{~m}$ hoogte $1,6 \mathrm{~m} / \mathrm{s}$ en op $4 \mathrm{~m}$ hoogte (ongeveer $1 \mathrm{~m}$ boven de bomen) $2,7 \mathrm{~m} / \mathrm{s}$. 


\section{Resultaten}

De resultaten van de metingen van de drift naar de grond naast het perceel zijn weergegeven in Bijlage 3 en de resultaten van de drift naar de lucht zijn weergegeven in Bijlage 4.

\subsection{Drift naar de grond naast het perceel}

De gemiddelde drift per spuittechniek tijdens bespuitingen in de volblad situatie (BBCH 90/92) staat weergegeven in figuur 3.1 en in tabel 3.1.

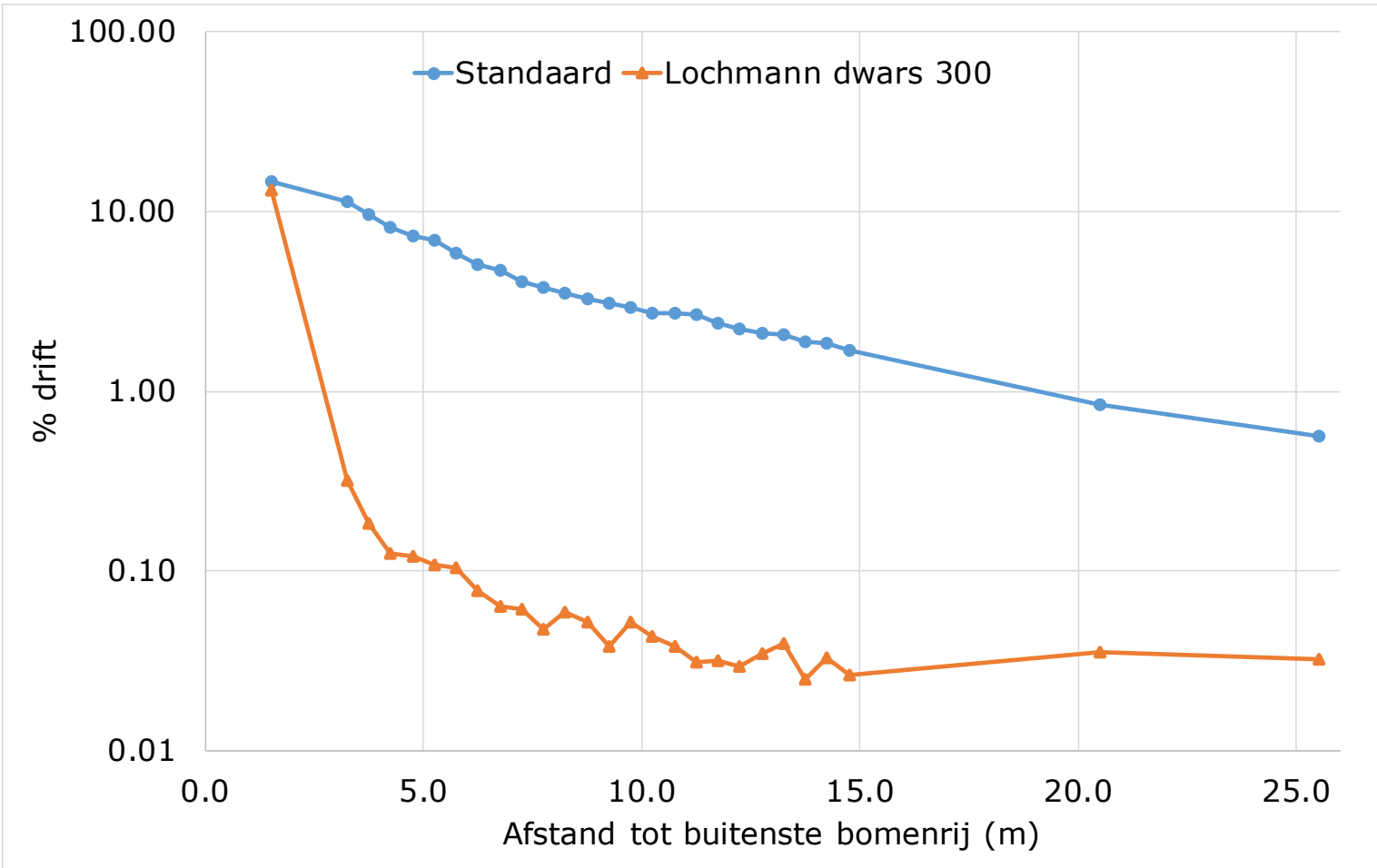

Figuur 3.1 Gemiddelde drift (\% van verspoten hoeveelheid spuitvloeistof per oppervlakte-eenheid) op verschillende afstanden vanaf het hart van de buitenste bomenrij bij bespuitingen van appelbomen in de volblad situatie (BBCH 90/92) met een standaard dwarsstroomspuit (Munckhof met ATR lila werveldoppen) en de Lochmann dwarsstroomspuit met TVI8001 spuitdoppen (DRD90), lage luchtinstelling, $300 \mathrm{rpm}$ aftakas toeren, 80\% dichte luchtklepinstelling naar buiten gerichte lucht in de buitenste 3 bomenrijen.

In figuur 3.1 en tabel 3.1 is te zien dat de standaard spuit (Munckhof dwarsstroom met ATR Lila werveldoppen) de meeste drift geeft. De Lochmann dwarsstroomspuit met TVI8001 spuitdoppen (DRD90), lage luchtinstelling, $300 \mathrm{rpm}$ aftakas toeren en $80 \%$ dichte luchtklepinstelling van de naar buiten gerichte lucht in de buitenste 3 bomenrijen geeft duidelijk een lagere drift. Dit is verder uitgewerkt in tabel 3.3 voor de verschillende evaluatiestroken. 
Tabel 3.1 Gemiddelde drift (\% van verspoten hoeveelheid spuitvloeistof per oppervlakte-eenheid) op verschillende afstanden vanaf het hart van de buitenste bomenrij bij bespuitingen van appelbomen in de volblad situatie (BBCH 90/92) met een standaard dwarsstroomspuit (Munckhof met ATR lila werveldoppen) en een Lochmann dwarsstroomspuit met TVI8001 spuitdoppen (DRD90), lage luchtinstelling, 300 rpm aftakas toeren, 80\% dichte luchtklepinstelling naar buiten gerichte lucht in de buitenste 3 bomenrijen.

\begin{tabular}{|c|c|c|}
\hline Afstand tot dop ( $m$ ) & Standaard & \\
\hline $25-26$ & 0,606 & 0,032 \\
\hline $20-21$ & 0,916 & 0,035 \\
\hline $14-141 / 2$ & 1,949 & 0,033 \\
\hline $131 / 2-14$ & 1,977 & 0,025 \\
\hline $121 / 2-13$ & 2,159 & 0,035 \\
\hline $12-12 \frac{1}{2}$ & 2,308 & 0,030 \\
\hline $11 \frac{1 / 2-12}{}$ & 2,472 & 0,032 \\
\hline $11-11 \frac{1 / 2}{2}$ & 2,758 & 0,031 \\
\hline $9-91 / 2$ & 3,076 & 0,038 \\
\hline $81 / 2-9$ & 3,269 & 0,052 \\
\hline $8-81 / 2$ & 3,486 & 0,059 \\
\hline $71 / 2-8$ & 3,768 & 0,048 \\
\hline $7-71 / 2$ & 4,065 & 0,061 \\
\hline $61 / 2-7$ & 4,736 & 0,063 \\
\hline $6-61 / 2$ & 5,119 & 0,078 \\
\hline $51 / 2-6$ & 5,834 & 0,104 \\
\hline $5-51 / 2$ & 6,921 & 0,108 \\
\hline
\end{tabular}

Tabel 3.2 Gemiddelde drift (\% van verspoten hoeveelheid spuitvloeistof per oppervlakte-eenheid) op de evaluatiestroken overeenkomend met teeltvrije zones van $3 m, 41 / 2 m, 6 m$ en $9 m$ bij bespuitingen van appelbomen in de volblad situatie (BBCH 90/92) met een standaard dwarsstroomspuit (Munckhof met ATR lila werveldoppen) en een Lochmann dwarsstroomspuit met TVI8001 spuitdoppen (DRD90), lage luchtinstelling, $300 \mathrm{rpm}$ aftakas toeren, $80 \%$ dichte luchtklepinstelling naar buiten gerichte lucht in de buitenste 3 bomenrijen.

\begin{tabular}{|c|c|c|c|c|c|c|c|c|c|c|c|c|c|c|c|c|}
\hline \multirow{3}{*}{$\begin{array}{l}\text { Techniek } \\
\text { Standaard }\end{array}$} & \multicolumn{16}{|c|}{ Afstand tot buitenste bomenrij (m) } \\
\hline & \multicolumn{4}{|c|}{$3 \mathrm{~m}$ teeltvrij } & \multicolumn{4}{|c|}{$41 / 2 \mathrm{~m}$ teeltvrij } & \multicolumn{4}{|c|}{$6 \mathrm{~m}$ teeltvrij } & \multicolumn{4}{|c|}{$9 \mathrm{~m}$ teeltvrij } \\
\hline & \multicolumn{2}{|c|}{ 3-7 } & \multicolumn{2}{|c|}{$41 / 2-51 / 2$} & \multicolumn{2}{|c|}{$41 / 2-81 / 2$} & \multicolumn{2}{|c|}{$6-7$} & \multicolumn{2}{|c|}{$6-10$} & \multicolumn{2}{|c|}{$71 / 2-81 / 2$} & \multicolumn{2}{|c|}{$9-13$} & \multicolumn{2}{|c|}{$101 / 2-11 \frac{1}{2}$} \\
\hline Lochmann & 0,14 & $\mathrm{~b}$ & 0,11 & $\mathrm{~b}$ & 0,08 & $\mathrm{~b}$ & 0,07 & $\mathrm{~b}$ & 0,06 & $\mathrm{~b}$ & 0,05 & $\mathrm{~b}$ & 0,04 & $b$ & 0,03 & $\mathrm{~b}$ \\
\hline
\end{tabular}

Verschillende letters in een kolom duiden op significante verschillen $(a<0,05)$

Op alle stroken geeft de standaard Munckhof dwarsstroomspuit voorzien van ATR Lila werveldoppen de hoogste drift. Op de strook 41/2-51/2 m behorende bij een $3 \mathrm{~m}$ teeltvrije zone was dit 7,14\%. De Lochmann dwarsstroomspuit met TVI8001 spuitdoppen (DRD90), lage luchtinstelling, 300 rpm aftakas toeren en $80 \%$ dichte luchtklepinstelling van de naar buiten gerichte lucht in de buitenste 3 bomenrijen geeft op alle stroken een significant lagere drift. Op 41/2-51/2 m werd 0,11\% drift gevonden. 


\subsection{Drift naar de lucht}

De gemiddelde drift naar de lucht voor de verschillende spuittechnieken zijn weergegeven in figuur 3.2 en tabel 3.3.

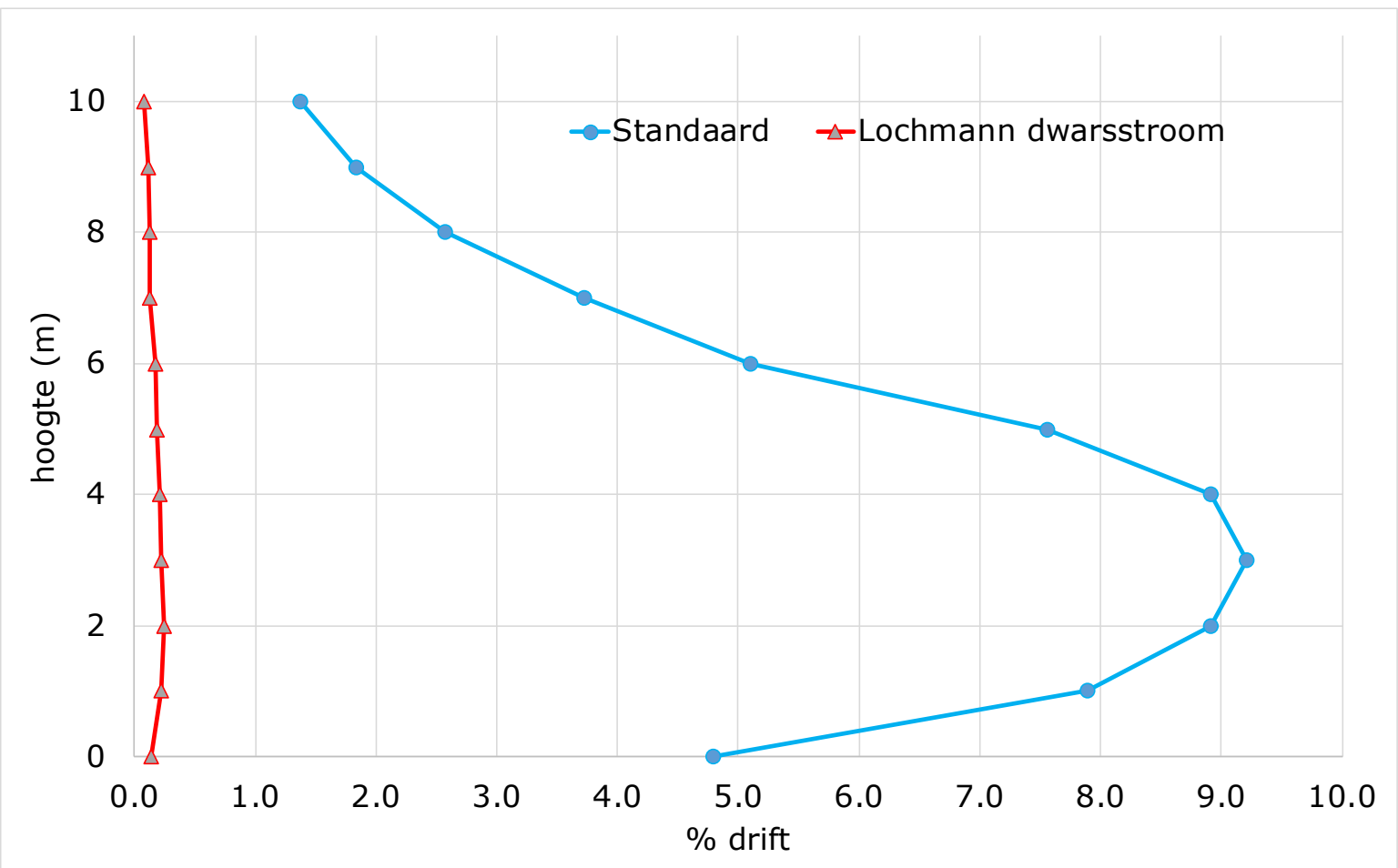

Figuur 3.2 Gemiddelde drift naar de lucht (\% van verspoten hoeveelheid spuitvloeistof per oppervlakte-eenheid) op verschillende hoogtes op $71 / 2 \mathrm{~m}$ vanaf het hart van de buitenste bomenrij bij bespuitingen van appelbomen in het volblad stadium (BBCH 90/92) met een standaard dwarsstroomspuit (Munckhof met ATR lila werveldoppen) en een Lochmann dwarsstroomspuit met TVI8001 spuitdoppen (DRD90), lage luchtinstelling, $300 \mathrm{rpm}$ aftakas toeren, 80\% dichte luchtklepinstelling naar buiten gerichte lucht in de buitenste 3 bomenrijen.

In figuur 3.2 en tabel 3.3 is te zien dat de standaard spuit (Munckhof dwarsstroom met ATR Lila werveldoppen) de meeste drift naar de lucht geeft. De Lochmann dwarsstroomspuit met TVI8001 spuitdoppen (DRD90), lage luchtinstelling, $300 \mathrm{rpm}$ aftakas toeren en $80 \%$ dichte luchtklepinstelling van de naar buiten gerichte lucht in de buitenste 3 bomenrijen geeft duidelijk een lagere drift naar de lucht.

Bij de standaard dwarsstroomspuit met ATR Lila spuitdoppen wordt op $10 \mathrm{~m}$ hoogte nog 1,23\% drift gevonden ( $2 \%$ van totaal op 0-10 m hoogte). Bij de Lochmann dwarsstroomspuit met TVI8001 spuitdoppen (DRD90), lage luchtinstelling, $300 \mathrm{rpm}$ aftakas toeren en $80 \%$ dichte luchtklepinstelling van de naar buiten gerichte lucht in de buitenste 3 bomenrijen wordt op $10 \mathrm{~m}$ hoogte 0,083\% drift gemeten (4,5\% van totaal op 0-10 m hoogte). Dit betekent dat bij beide spuittechnieken hoog genoeg gemeten is om op het hoogste meetpunt $(10 \mathrm{~m})$ meer dan $90 \%$ van de totaal opgevangen drift naar de lucht (0-10 m) op te vangen (ISO22866). De resultaten van de driftmetingen naar de lucht zijn verder uitgewerkt in tabel 3.4 . 
Tabel 3.3 Gemiddelde drift naar de lucht (\% van verspoten hoeveelheid spuitvloeistof per oppervlakte-eenheid) op verschillende hoogtes op 71/2 $\mathrm{m}$ vanaf het hart van de buitenste bomenrij bij bespuitingen van appelbomen in het volblad stadium (BBCH 90/92) met een standaard dwarsstroomspuit (Munckhof met ATR lila werveldoppen) en een Lochmann dwarsstroomspuit met TVI8001 spuitdoppen (DRD90), lage luchtinstelling, $300 \mathrm{rpm}$ aftakas toeren, $80 \%$ dichte luchtklepinstelling naar buiten gerichte lucht in de buitenste 3 bomenrijen.

\begin{tabular}{|c|c|c|}
\hline Hoogte (m) & Standaard & Lochmann dwarsstroom \\
\hline 0 & 5.017 & 0.140 \\
\hline 1 & 7.932 & 0.224 \\
\hline 3 & 9.327 & 0.225 \\
\hline 4 & 9.420 & 0.208 \\
\hline 6 & 4.930 & 0.180 \\
\hline 7 & 3.240 & 0.123 \\
\hline 8 & 2.300 & 0.126 \\
\hline 9 & 1.632 & 0.110 \\
\hline
\end{tabular}

Tabel 3.4 Gemiddelde drift naar de lucht (\% van verspoten hoeveelheid spuitvloeistof per oppervlakte-eenheid) op verschillende hoogtes op 71/2 $\mathrm{m}$ vanaf het hart van de buitenste bomenrij bij bespuitingen van appelbomen in het volblad stadium (BBCH 90/92) met een standaard dwarsstroomspuit (Munckhof met ATR lila werveldoppen) en een Lochmann dwarsstroomspuit met TVI8001 spuitdoppen (DRD90), lage luchtinstelling, $300 \mathrm{rpm}$ aftakas toeren, $80 \%$ dichte luchtklepinstelling naar buiten gerichte lucht in de buitenste 3 bomenrijen.

\begin{tabular}{|c|c|c|c|c|c|c|c|c|}
\hline \multirow{2}{*}{$\begin{array}{l}\text { Techniek } \\
\text { Standaard }\end{array}$} & \multicolumn{8}{|c|}{$\%$ drift op hoogte $(m)$} \\
\hline & 7.76 & $\mathrm{a}$ & 7.87 & $\mathrm{a}$ & 2.67 & $\mathrm{a}$ & 5.60 & $\mathrm{a}$ \\
\hline
\end{tabular}

Verschillende letters in een kolom duiden op significante verschillen $(a<0,05)$

Over alle hoogtes $(0-10 \mathrm{~m})$ geeft de standaard dwarsstroomspuit de hoogste drift naar de lucht. Gemiddeld over 0-10 m hoogte was de drift op 7,5 m van de buitenste bomenrij voor de standaard dwarsstroomspuit 5,60\%. De Lochmann dwarsstroomspuit met TVI8001 spuitdoppen (DRD90), lage luchtinstelling, $300 \mathrm{rpm}$ aftakas toeren en $80 \%$ dichte luchtklepinstelling van de naar buiten gerichte lucht in de buitenste 3 bomenrijen geeft over 0-10 m met 0,17\% een significant lagere drift naar de lucht. 


\section{$4 \quad$ Discussie}

\section{Driftreductie}

Ten opzichte van de standaardbespuiting met de Munckhof dwarsstroomspuit gecombineerd met ATR Lila werveldoppen geeft de Lochmann dwarsstroomspuit met TVI8001 spuitdoppen (DRD90), lage luchtinstelling, 300 rpm aftakas toeren en met het Air Closing System 80\% dichte luchtklepinstelling van de naar buiten gerichte lucht in de buitenste 3 bomenrijen bij de drift naar de grond op alle stroken een significante driftreductie tussen $98,1 \%-98,7 \%$ (tabel 4.1 ). Bij een teeltvrije zone van $3 \mathrm{~m}$ wordt op de strook $4 \frac{112-51 / 2}{m}$ een driftreductie gevonden van $98,4 \%$.

Bij de drift naar de lucht, gemiddeld over 0-10 m hoogte op 7,5 m van de laatste bomenrij, geeft de Lochmann dwarsstroomspuit met TVI8001 spuitdoppen (DRD90), lage luchtinstelling, 300 rpm aftakas toeren en met het Air Closing System 80\% dichte luchtklepinstelling van de naar buiten gerichte lucht in de buitenste 3 bomenrijen een significante driftreductie van 97,0\%.

Tabel 4.1 Gemiddelde driftreductie (\%) ten opzichte van de referentie spuit (Munckhof dwarsstroomspuit voorzien van ATR Lila werveldoppen) op de verschillende evaluatiestroken (overeenkomend met teeltvrije zones van $3 \mathrm{~m}, 4 \frac{1}{2} \mathrm{~m}, 6 \mathrm{~m}$ en $9 \mathrm{~m}$ ) en naar de lucht (gemiddeld over 0-10 $m$ hoogte) op 7,5 $m$ van de laatste bomenrij bij bespuitingen van appelbomen in het volblad stadium (BBCH 90/92) met een standaard dwarsstroomspuit (Munckhof met ATR lila werveldoppen) en Lochmann dwarsstroomspuit met TVI8001 spuitdoppen (DRD90), lage luchtinstelling, 300 rpm aftakas toeren, $80 \%$ dichte luchtklepinstelling naar buiten gerichte lucht in de buitenste 3 bomenrijen.

\begin{tabular}{|c|c|c|c|c|c|c|c|c|c|}
\hline Techniek & \multicolumn{9}{|c|}{ Driftreductie $(\%)$ op } \\
\hline $\begin{array}{l}\text { Lochmann } \\
\text { dwarsstroom }\end{array}$ & 98,1 & 98,4 & 98,4 & 98,6 & 98,5 & 98,5 & 98,6 & 98,7 & 97,0 \\
\hline
\end{tabular}




\section{$5 \quad$ Conclusie}

Bij driftmetingen tijdens bespuitingen van een appelboomgaard in het volblad stadium (BBCH 90/92) met de Lochmann dwarsstroomspuit met TVI8001 spuitdoppen (DRD90), lage luchtinstelling, $300 \mathrm{rpm}$ aftakas toeren en met het Air Closing System 80\% dichte luchtklepinstelling van de naar buiten gerichte lucht in de buitenste 3 bomenrijen werd in vergelijking met een referentie boomgaard bespuiting bij een $3 \mathrm{~m}$ teeltvrije zone op de strook 41/2-51/2 $\mathrm{m}$ vanaf de buitenste bomenrij een driftreductie gevonden van $98,4 \%$. Op grond van dit resultaat kan deze spuittechniek in de driftreducerende techniek (DRT) klasse 97,5 ingedeeld worden.

Bij de drift naar de lucht, gemiddeld over 0-10 m hoogte op 7,5 m van de laatste bomenrij, geeft de Lochmann dwarsstroomspuit met TVI8001 spuitdoppen (DRD90), lage luchtinstelling, 300 rpm aftakas toeren en met het Air Closing System 80\% dichte luchtklepinstelling van de naar buiten gerichte lucht in de buitenste 3 bomenrijen een significante driftreductie van 97,0\%. 


\section{Literatuur}

Ctgb, 2018. Evaluation Manual for the Authorisation of Plant protection products and Biocides according to Regulation (EC) No 1107/2009 NL part Plant protection products. Chapter 6 Fate and behaviour in the environment: behaviour in surface water and sediment version 2.2; January 2018. http://www.ctgb.nl/

EZ, 2013. Gezonde Groei, Duurzame Oogst. Tweede nota duurzame gewasbescherming, periode 2013 tot 2023. Ministerie van Economische Zaken, Den Haag. 2013. 46p.

Gezondheidsraad, 2014. Gewasbescherming en omwonenden. Gezondheidsraad, publicatienr. 2014/02, Den Haag. 2014. 194p.

Huijsmans, J.F.M., H.A.J. Porskamp \& J.C. van de Zande, 1997. Drift(beperking) bij de toediening van gewasbeschermingsmiddelen. Evaluatie van de drift van spuitvloeistof bij bespuitingen in de fruitteelt, de volveldsteelten. en de boomteelt (stand van zaken december 1996). IMAG-DLO Rapport 97-04, IMAG, Wageningen, 38 pp.

I\&W, 2017. Regeling van de Staatssecretaris van Infrastructuur en Waterstaat, van 10 november 2017, nr. IENM/BSK-2017/254105, tot wijziging van de Activiteitenregeling in verband met de vermindering van emissies van gewasbeschermingsmiddelen in de glastuinbouw en open teelten. Staatscourant $2017 \mathrm{Nr} .60506$

ISO 22866,2005 . Equipment for crop protection - Methods for the field measurement of spray drift. International Standardisation Organisation, Geneva. 2005.

ISO-22369, 2006. Crop protection equipment - Drift classification of spraying equipment. Part 1. Classes. International Organization for Standardization, Geneva.

Michielsen, J.M.G.P., Wenneker, M., Zande, JC van de \& Heijne, B., 2007. Contribution of individual row sprayings to airborne drift spraying an apple orchard. In: E. Gil, F. Solanelles, S. Planas, J.R. Rossell \& L. Val (eds). 8th Workshop on Spray Apllication Techniques in Fruit Growing June 2005 Barcelona, Book of Abstracts, Universitat Politècnica de Catalunya, Generalitat de Catalunya, Universitat de Lleida, Barcelona, 2007. p.37-46

Payne et al., 2006. Genstat Release 9.2,

Stallinga, H., M. Wenneker, J.C. van de Zande, J.M.G.P. Michielsen, P. van Velde, A.T. Nieuwenhuizen \& L.L.P. Luckerhoff, 2013. Drift en driftreductie van de innovatieve drierijige emissiearme fruitteeltspuit van KWH. Wageningen UR Plant Research International, Plant Research International Rapport 458, Wageningen. 2013. 92 p.

Stallinga, H., P. van Velde, J.M.G.P. Michielsen, M. Wenneker \& J.C. van de Zande, 2016. Driftreductie KWH Mistral boomgaardspuit met VLBS. Effect van doptype en luchthoeveelheid. Wageningen UR, Plant Research International, Wageningen, WUR-PRI Rapport 643. 2016. 36p.

Stallinga, H., P. van Velde, J.M.G.P. Michielsen, M. Wenneker \& J.C. van de Zande, 2017. Driftreductie H.S.S. CF boomgaardspuit met blaasmondverstelling en lage luchthoeveelheid. Wageningen Research, Wageningen, Rapport WPR-675. 2017. 50p.

Stallinga, H., P. van Velde, J.M.G.P. Michielsen, M. Wenneker \& J.C. van de Zande, 2018. Driftreductie Munckhof MAS 3 rijen boomgaardspuit; Effect van VARIMAS variabele luchtondersteuning en Randrijen instelling. Wageningen Research, Wageningen, Rapport WPR-759. 2018. 38 p.

TCT, 2017a. Beoordelingssystematiek emissiereducerende maatregelen open teelt. versie 15 december 2017. [https://www.helpdeskwater.nl/onderwerpen/emissiebeheer/agrarisch/openteelt/driftreducerende/]

TCT, 2017b. Meetprotocol vaststellen driftreductie spuittechnieken [versie 1 juli 2017]. [https://www.helpdeskwater.nl/onderwerpen/emissiebeheer/agrarisch/openteelt/driftreducerende/]

TCT, 2018a. Lijst met indeling van spuittechnieken in Driftreducerende Techniek-klassen (DRTklassen) (DRT lijst). [https://www.helpdeskwater.nl/onderwerpen/emissiebeheer/agrarisch/openteelt/driftreducerende/]

TCT, 2018b. Lijst met indeling van spuitdoppen in Driftreducerende Dop-klassen (DRD-klassen) (DRDlijst). [https://www.helpdeskwater.nl/onderwerpen/emissiebeheer/agrarisch/openteelt/driftreducerende/] 
VW, VROM, LNV, 2007. Wijziging van het Lozingenbesluit open teelt en veehouderij en enige andere besluiten (actualisering lozingenvoorschriften). Staatsblad 2007 143, 35p.

Wenneker, M., B. Heijne \& J.C. van de Zande, 2004. Invloed venturi-spleetdoppen en luchtondersteuning op emissies bij bespuitingen in de fruitteelt. Praktijkonderzoek Plant \& Omgeving, sector Fruit, PPO-fruit Rapport 2004-03, Randwijk, 2004.

Zande, J.C. van de, M.C. Butler Ellis, M. Wenneker, P.J. Walklate \& M. Kennedy, 2014. Spray drift and bystander risk from fruit crop spraying. International Advances in Pesticide Application, Aspects of Applied Biology 122, 2014. p. 177-186.

Zande, J.C. van de, H.J. Holterman, J.F.M. Huijsmans \& M. Wenneker, 2018. Spray drift for the assessment of exposure of aquatic organisms to plant protection products in the Netherlands. Part 2: Sideways and upward sprayed fruit and tree crops. Wageningen UR, WPR Report 564, Wageningen. 2018. 


\section{Bijlage 1 Script statistische analyse}

IRREML

$[$ PRINT $=$ MOD, COM,MEAN,EFF, WALD, DEV; $\backslash$

$\mathrm{DISTR}=\mathrm{BIN} ; \mathrm{LINK}=\mathrm{LOGIT} ; \mathrm{DISP}=* ;$

RANDOM $=$ hh $*$ rij $; \backslash$

FIXED = techniek; $\backslash$

$\mathrm{PSE}=\mathrm{ALLD} ; \mathrm{CHECK}=\mathrm{YES}$; meth $=$ fisher $]$ zone; $\mathrm{NBIN}=100 ; \backslash$

RESID=Rest; FITTED =zoneFIT 


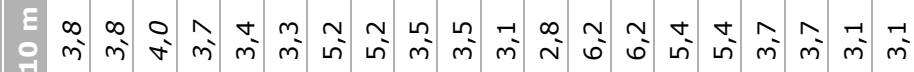

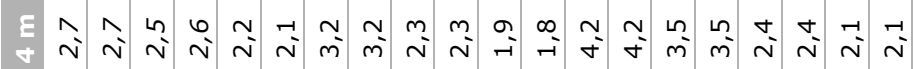

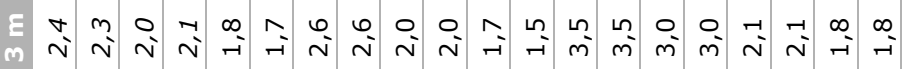

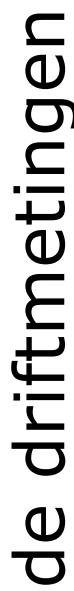

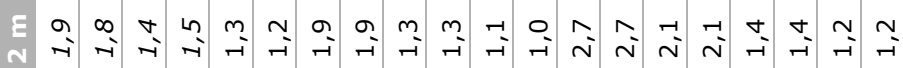

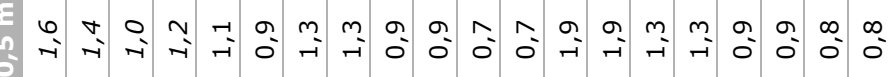

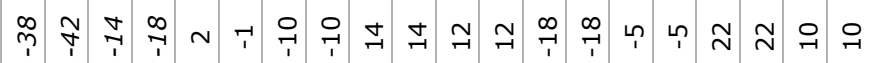

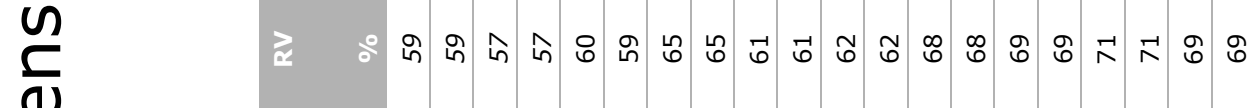

ש

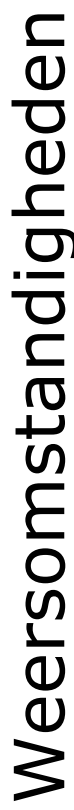

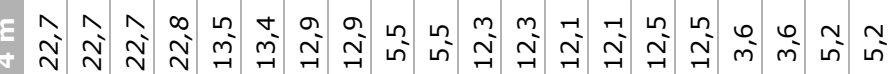

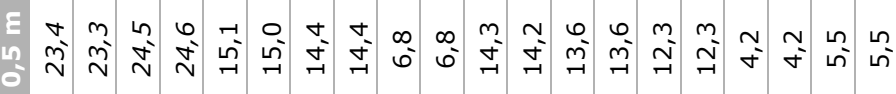

N

(1)

0

$\frac{0}{10}$

\#HnmbL

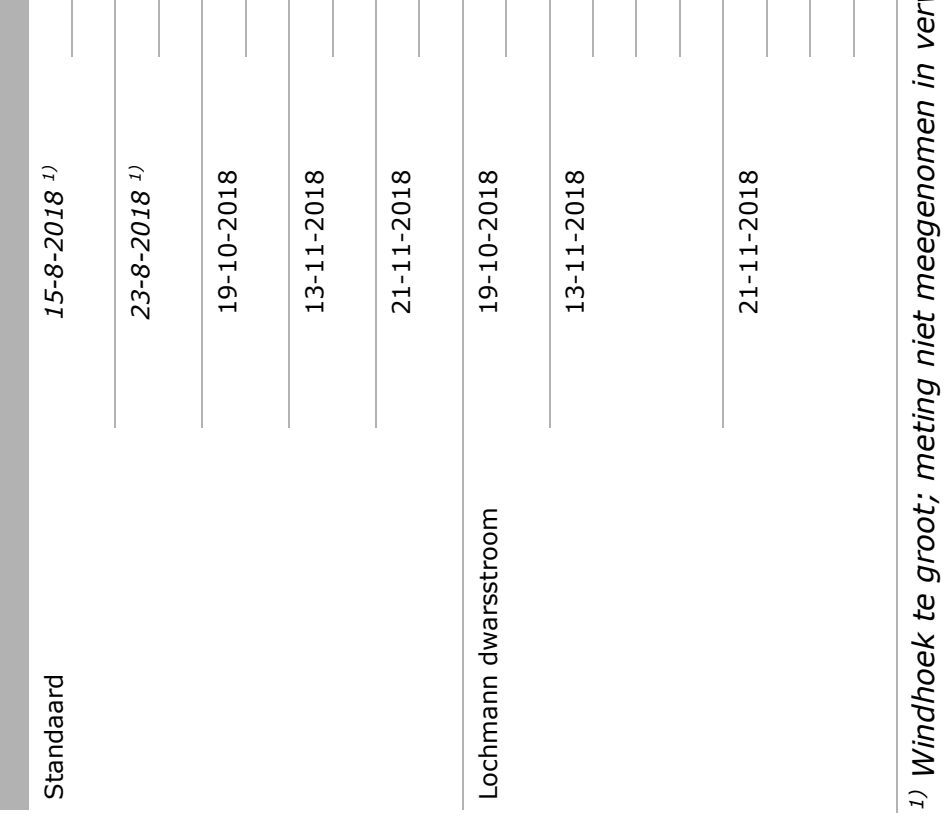




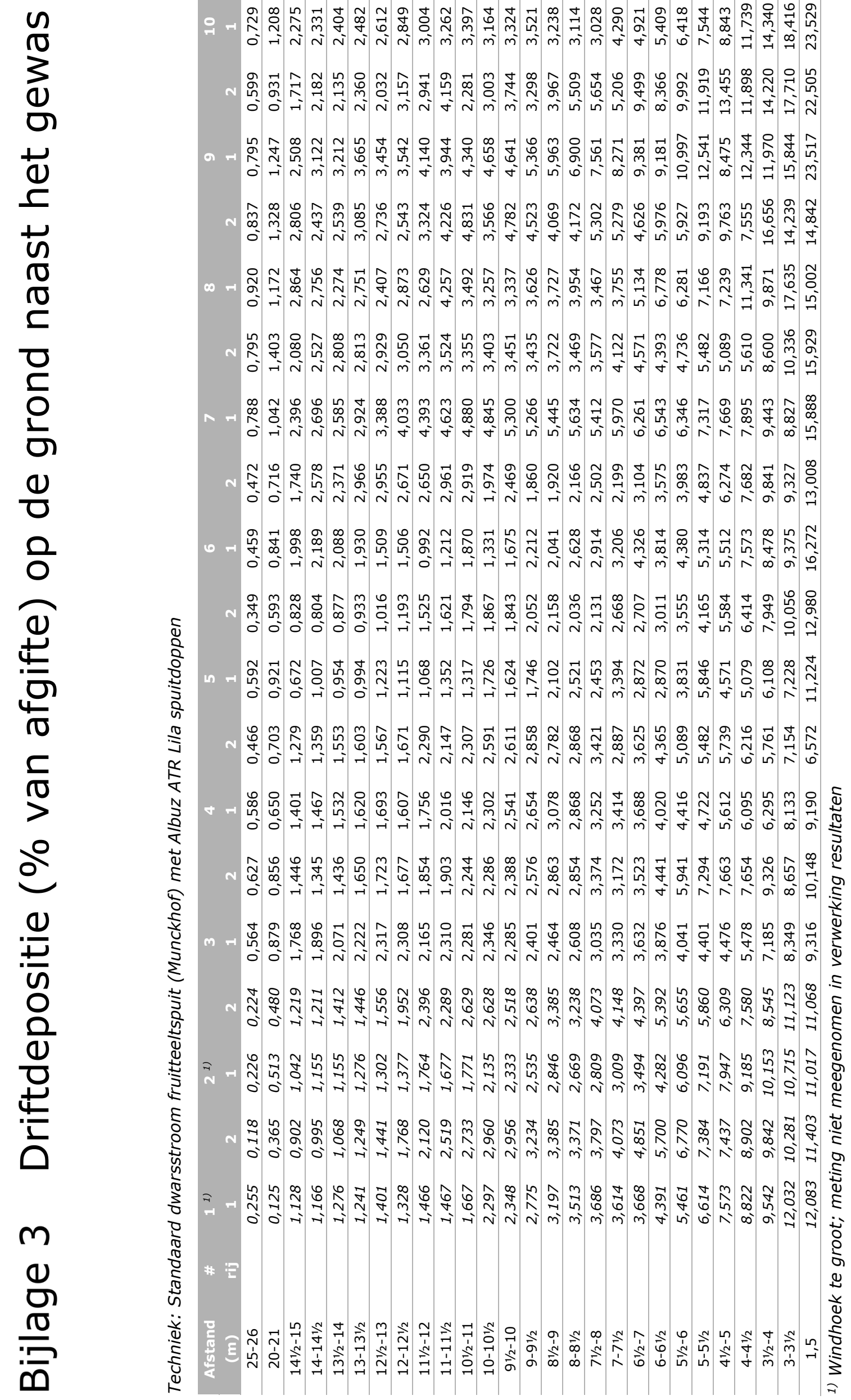




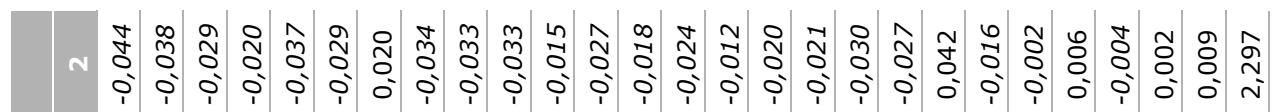

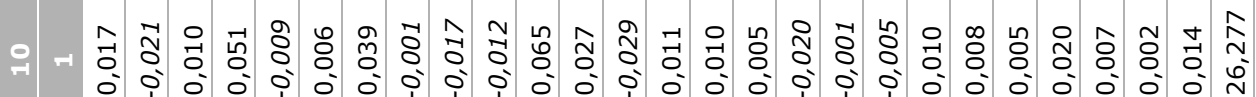
100

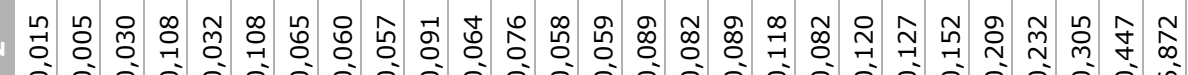

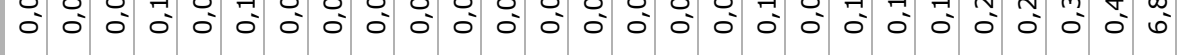

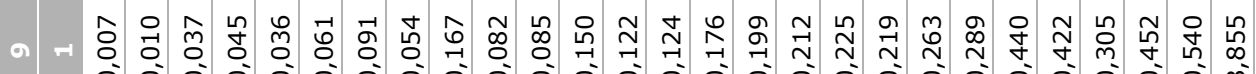

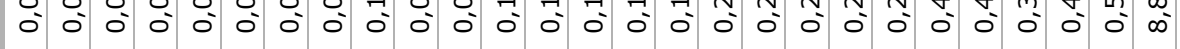

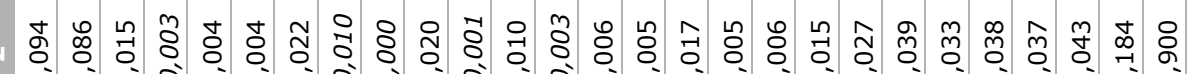

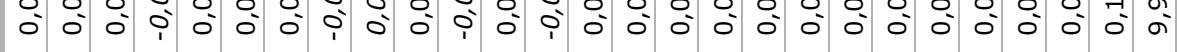

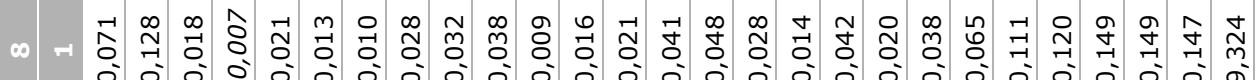
- 00 o

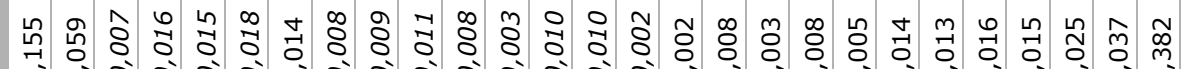

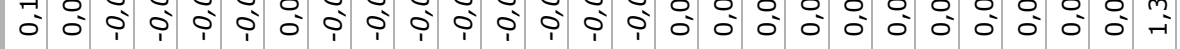

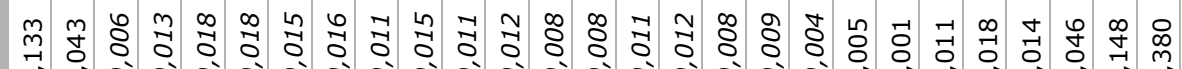

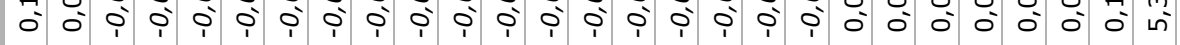

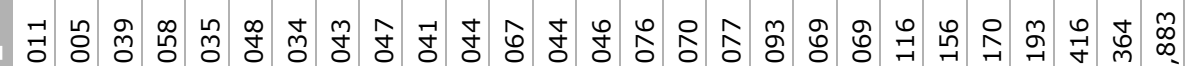

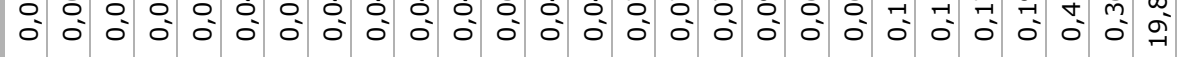

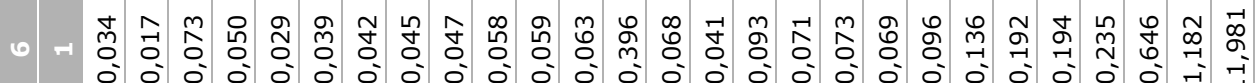

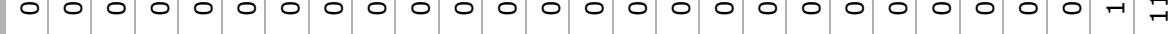

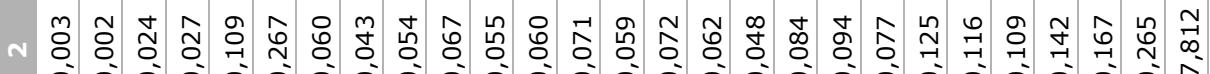

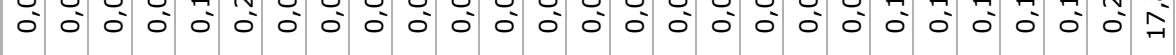

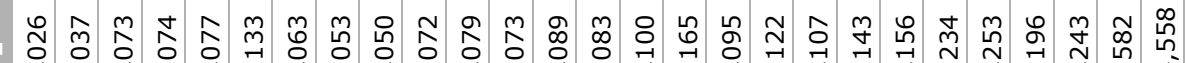

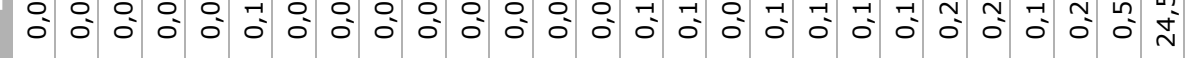

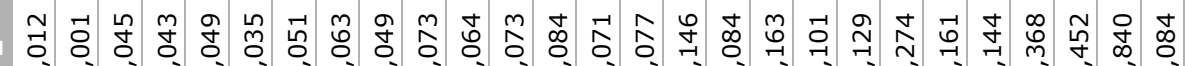

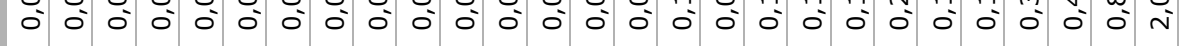

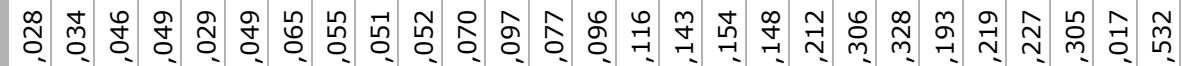

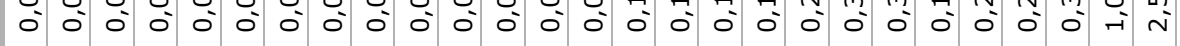

N N

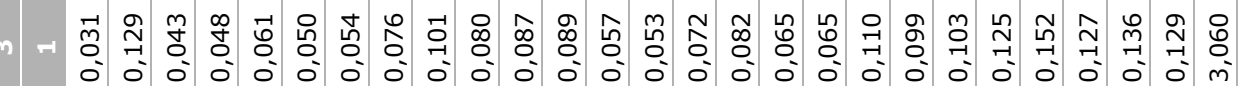

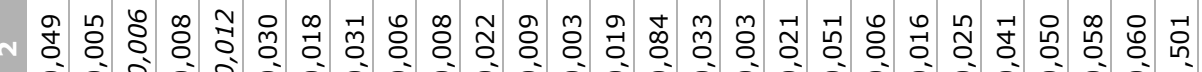

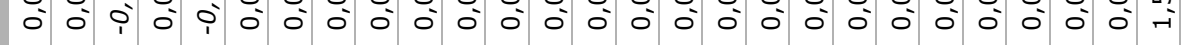

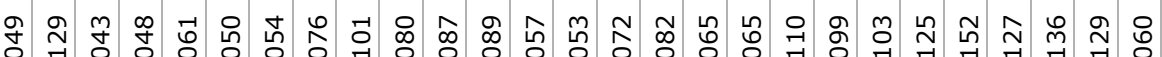

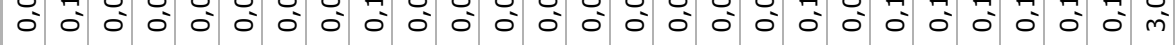

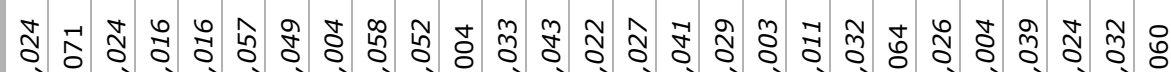

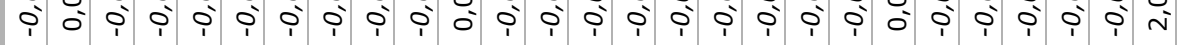

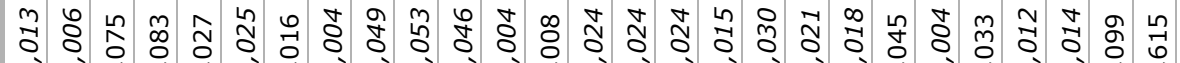

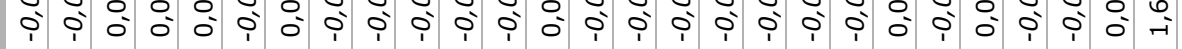




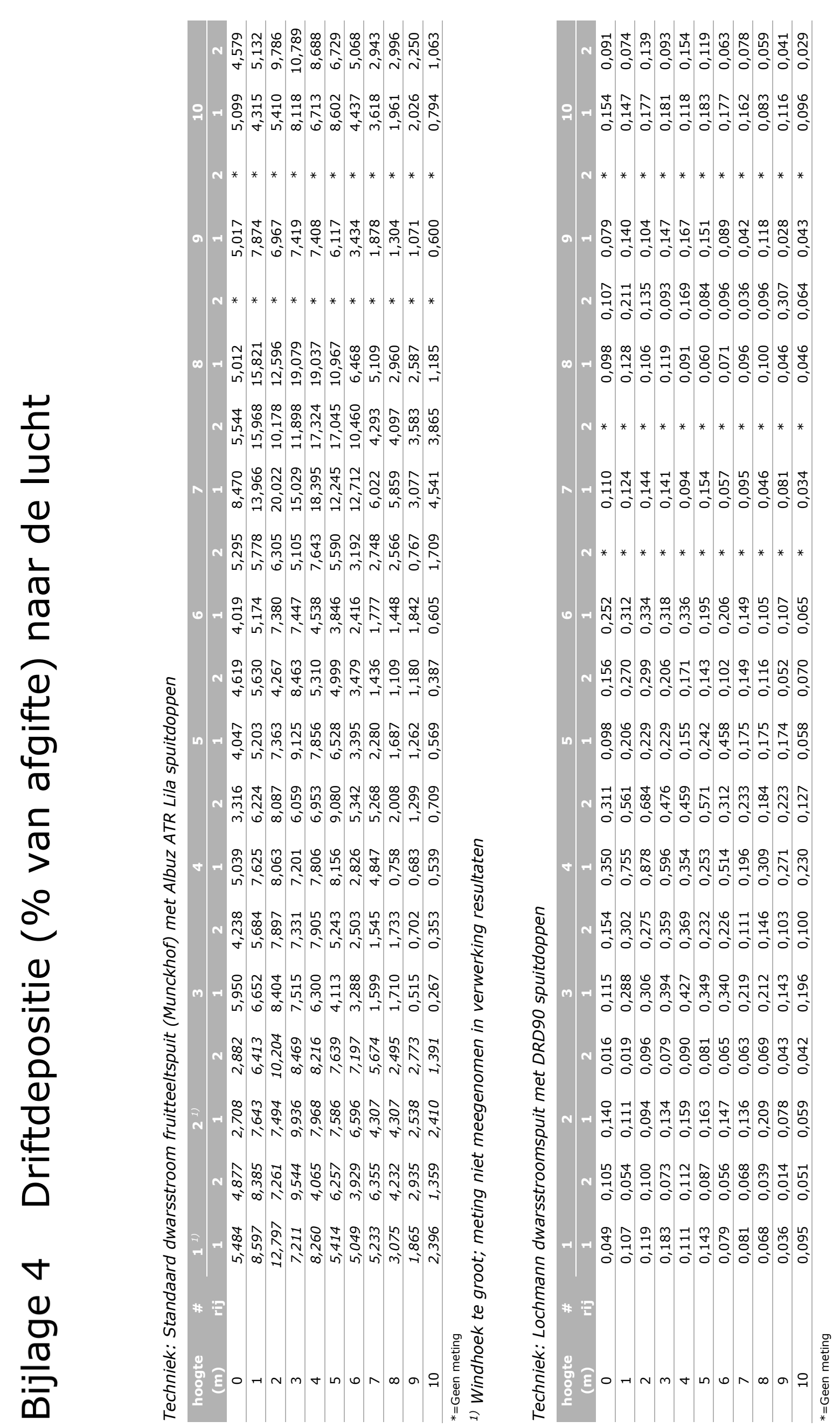


Correspondentie adres voor dit rapport: Postbus 16

6700 AA Wageningen

T 0317480700

www.wur.nl/plant-research

Rapport WPR-881
De missie van Wageningen University \& Research is 'To explore the potential of nature to improve the quality of life'. Binnen Wageningen University \& Research bundelen Wageningen University en gespecialiseerde onderzoeksinstituten van Stichting Wageningen Research hun krachten om bij te dragen aan de oplossing van belangrijke vragen in het domein van gezonde voeding en leefomgeving. Met ongeveer 30 vestigingen, 5.000 medewerkers en 10.000 studenten behoort Wageningen University \& Research wereldwijd tot de aansprekende kennisinstellingen binnen haar domein. De integrale benadering van de vraagstukken en de samenwerking tussen verschillende disciplines vormen het hart van de unieke Wageningen aanpak. 



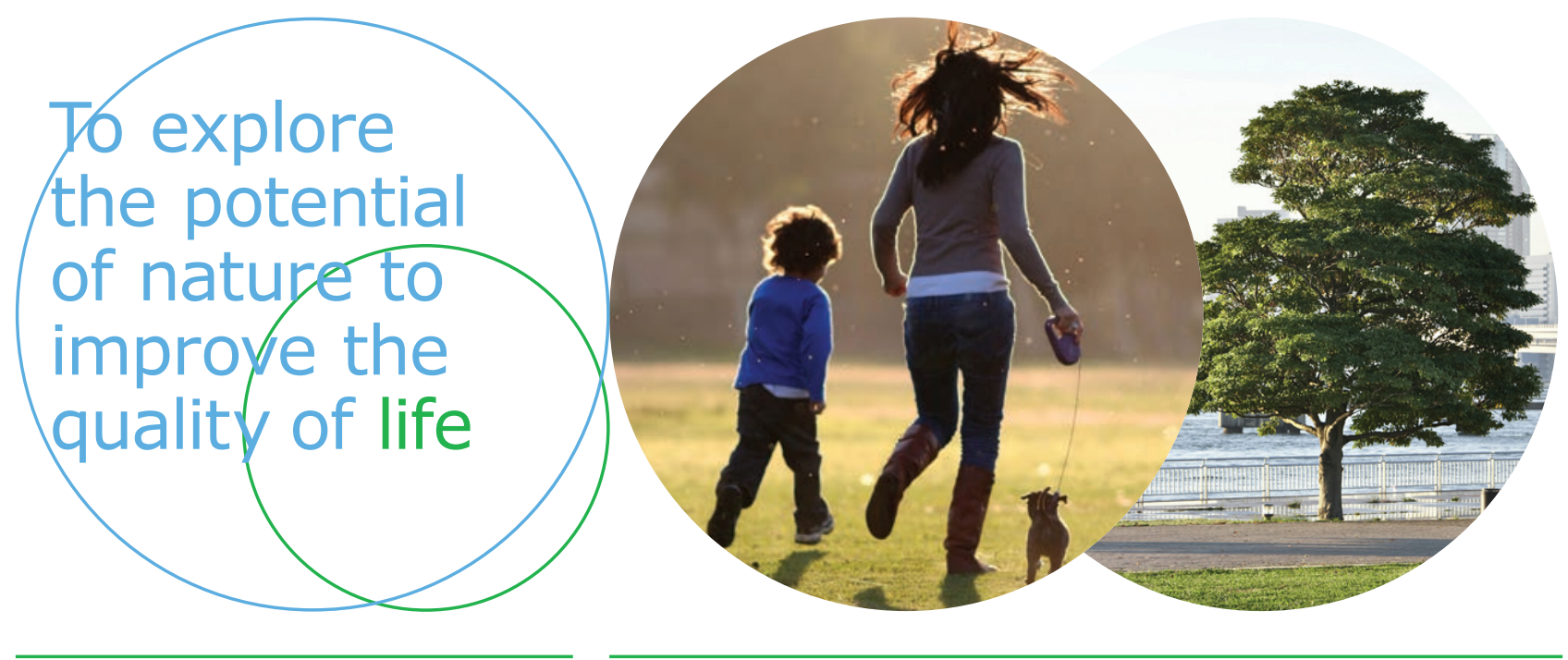

Correspondentie adres voor dit rapport: Postbus 16

6700 AA Wageningen

T 0317480700

www.wur.nl/plant-research

Rapport WPR-881
De missie van Wageningen University \& Research is 'To explore the potential of nature to improve the quality of life'. Binnen Wageningen University \& Research bundelen Wageningen University en gespecialiseerde onderzoeksinstituten van Stichting Wageningen Research hun krachten om bij te dragen aan de oplossing van belangrijke vragen in het domein van gezonde voeding en leefomgeving. Met ongeveer 30 vestigingen, 5.000 medewerkers en 10.000 studenten behoort Wageningen University \& Research wereldwijd tot de aansprekende kennisinstellingen binnen haar domein. De integrale benadering van de vraagstukken en de samenwerking tussen verschillende disciplines vormen het hart van de unieke Wageningen aanpak. 